\title{
Yulia Bosworth*
}

\section{High vowel distribution and trochaic markedness in Québécois}

DOI 10.1515/tlr-2016-0009

\begin{abstract}
This paper argues for quantity-sensitive, trochaic foot structure in Québécois French, which allows for a unified prosodic account of the variable distribution of tenseness of high vowels in non-final syllables. Following Montreuil (Montreuil, Jean-Pierre. 2004a. Fragmenting weight in Scottish English. In Monica Pulki (ed.), La tribune internationale des langues vivantes, 36, 114-22. Paris. Montreuil, Jean-Pierre. 2004b. The Computation of weight in English and in Québec French. First PAC Workshop 23-24 April 2004, Université de Toulouse le Mirail.) a grammatical, sonority-based surface weight distinction is assumed for Québécois French vowels, with tense high vowels associated to a full mora $\mu$, while lax high vowels are associated to a hypomora $\lambda$, a weight value less than $\mu$. The weight is shown to be regulated at the level of the minimally monomoraic foot, which can be expanded to include an adjacent syllable in words consisting of more than two syllables, following the proposed Trochaic Markedness Hierarchy, based on the following three ranked principles: 1) quantitative minimum: light and heavy rimes are preferred to superlight $(\lambda)$ rimes, 2) quantitative evenness: even trochees are preferred to uneven trochees, and 3) quantitative dominance: the left branch that is heavier than the right branch is preferred to the left branch that is lighter. Possible shapes of the trochee are shown to be aligned with alternating surface realizations of high vowels.
\end{abstract}

Keywords: Quebec French, high vowels, vowel reduction, foot, phonological weight, sonority

\section{Introduction}

Consistently interesting and interestingly inconsistent, the distribution of the surface variant pairs of high vowels in Québécois French - [i]/[I], [y]/[y] and [u]/ [u] - has received a great deal of attention from phonologists in the last five decades. This interest has resulted in an extensive body of proposals accounting for some aspects of the behavior of these vowels. Any unified analysis is

*Corresponding author: Yulia Bosworth, Binghamton University, Binghamton, NY, USA, E-mail: bosworth@binghamton.edu 
potentially complicated by the fact that their distribution in regards to tenseness is complementary in one type of position (word-final environment), and appears to be in free variation in another (non-final environment). In word-final syllables, high vowels are lax if the syllable is closed and tense if it is open: [ami] "ami" and [gamm] "gamine". In the non-final environment, the same tendency is observed, but there is alternation: [ny/ymero] "numéro", [ami/rtje] "amitié", [vi/iktor] "Victor". Furthermore, in a significant number of words with an obligatorily lax high vowel in the final closed syllable and at least one other high vowel in a non-final open syllable, the latter may also surface as lax: [butrk] "boutique”, [Inedit], "inédite”, [similityd] "similitude”. The presence of a non-final lax high vowel in these types of forms is commonly viewed in the literature as high vowel laxing harmony, triggered by the high segment in the final syllable (Dumas 1976, Walker 1984, Poliquin 2006). In addition to variation in tenseness, high vowels may also surface as devoiced or fail to surface altogether in a subset of non-final environments: [ekŪte] "écouter”, [kamzol] "camisole".

The distribution of high vowels in Québécois is briefly illustrated in a representative data set below, reproducing well-known examples from Dumas (1976), Walker (1984) and (Déchaine 1991):

(1) Brief summary of high vowel distribution in Québécois

a. Final closed syllable : lax

'route' road [rut] *[rut]

'Beyrouth' Beyrouth [berut] *[berut]

b. Final open syllable : tense

'vie' life [vi] *[vi]

'envie' desire [ãvi] *[ãvi]

c. Final syllable ending in a voiced continuant : tense and lengthened

'mur' wall [my:r] / [my $\left.{ }^{\mathrm{y}} \mathrm{r}\right] *[\mathrm{mrr}] \quad *[\mathrm{my}: \mathrm{r}]$

'juge' judge [3y:3] / [3y $\left.\mathrm{y}^{\mathrm{y}}: 3\right] \quad$ *[3y3] *[3y:3]

d. Non-final open syllable: tense or lax

'pilule' pill [pilyl] [prlyl]

'tribu' tribe [triby] [triby]

'mitaine' mitten [mitcn] [mitcn]

'numéro' number [nymero] [nymero]

'amitié' friendship [amitje] [amitje]

e. Non-final closed syllable: tense or lax

'rupture' break [rypty:r] [rypty:r]

'Victor' Victor [vikto:r] [vikto:r] 
f. Non-final syllable: devoiced 'étouffement' strangling [etu/ufmã] [etu/Uofmã]

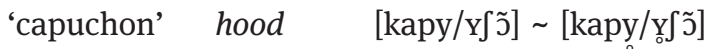

g. Non-final open syllable: deleted
'camisole' slip
[kamzol]
'population' population [poplasjõ]

The proposed solutions include a multitude of rule-based treatments, consisting of a series of derivational transformations rooted in syllable structure (Dumas 1976 etc), a metrical template analysis positing rhymes of varying prominence (Déchaine 1991), a proposal based on sonority-based weight number minima at the level of the syllable (Montreuil 2005), and an asyllabic, segmental linkbased account (Côté 2008). These analyses have contributed to our overall understanding of the behavior of high vowels by treating a subset of forms or a subset of environments. For example, a rule-based approach in Dumas (1976) focuses on a dataset with a possible laxing harmony analysis, i. e. lax high vowels in non-final open syllables in forms that contain a high vowel in the final syllable, the potential harmony trigger. This type of analysis is able to account for the optional presence of a lax high vowel in forms like [rutin] "routine", containing an obligatorily lax high vowel in the final closed syllable, and those derived from such forms: [rutinje] "routinier", in which the morphological boundary preserves the closed nature of the syllable of the related form that supplies the necessary laxing environment: rutin|je. It also extends to forms which contain a high tense vowel word-finally, [trrby], positing a dissimilatory effect. However, forms with no high vowel in a syllable to the right or a morphologically related form, such as [nymero] or [amitje], are left out of the account. Côté (2008), searching for a syllable-independent solution, sets aside harmony-motivated forms and proposes an insightful analysis based on the link between a vowel and a following consonant, but restricts her dataset to the $\mathrm{VC}_{1} \mathrm{C}_{2} \mathrm{~V}$ environment as in [vi/iktor] or [sy/ylt ã], closed syllables in the traditional, syllabic, approach.

In this paper, I develop a unified prosodic analysis of the well-known variable realization of high vowels in non-final open syllables in Québécois (cf Dumas 1974, 1976, 1978, 1981, Walker 1984, Déchaine 1991, Poliquin 2006), with a particular focus on the tense/lax/0 alternation. In positing quantitysensitive foot structure in Québécois, I follow the analysis of Québécois high vowel realization in final syllables developed in Montreuil (2004a,b): a segment's sonority serves as basis for weight assignment, with the total weight of the given rhyme determining the surface realization of high vowels in the final 
environment. ${ }^{1}$ Under the current analysis, optional surface realizations in the non-final environment result from a possibility of multiple instantiations of the moraic trochee allowed by the grammar of this language. These shapes are assigned by the Trochaic Markedness Hierarchy, developed here for Québécois.

\section{Previous analyses of metrical structure in French}

The traditional view of the prosody of Standard French (SF) attributes very low functionality to the prosodic units of mora and foot. SF is a syllable-timed language with fixed phrase-final stress (cf Delattre 1966). To the extent that the foot can be of relevance, it is largely viewed to be redundant in that it is coextensive with the syllable (cf Selkirk 1978). The demarcative, fixed nature of phonetic stress renders the foot irrelevant for stress assignment: the last foot/ syllable of (a)(li)(ga)('tor) receives stress, as does the last syllable of "faculté": (fa)(kyl)('te), without taking account of the composition of the rhyme. To account for the word-final prominence, the type of foot most often proposed is a right-branching structure, or an iamb (cf Archibald 1996, Charette 1991, Phinney 1980, Paradis and Deshaies 1991). Despite the wide-spread assumption that SF prosody is not generally characterized by quantity-sensitivity, there are a number of length-related phenomena and prosodic-morphological processes that have been analyzed quantitatively: a timing-slots based account of masculine final rhymes (Plénat 1987), Voiced Continuant Lengthening and Schwa Compensatory Lengthening (Montreuil 1992, 1995a), schwa distribution (Selkirk 1978, Montreuil 1993, Bullock 1994), truncation and reduplication processes (Scullen 1997), and Québécois high vowel distribution in monosyllables (Montreuil 2004b).

Given the absence of motivation to posit foot structure based on the location of stress, two other kinds of feet have been proposed in French: an uneven trochee to account for the distribution of the underlying schwa (Selkirk 1978, further elaborated in Montreuil 1993 and Bullock 1994), and an iambic foot that serves as the mapping template for outputs of prosodic-morphological operations such as abbreviations, acronyms, hypocoristics and reduplication (Scullen

1 At the exclusion of the phenomenon of Voiced Continuant Lengthening, illustrated in (1c), given that it is limited to the final syllables. For a $\mu$-share based-analysis of VCL with superlight high vowels, see Bosworth (2011). 
1997). Crucially, these analyses introduce and motivate two factors critical to the current proposal: a branching foot and quantity-sensitivity in French.

\subsection{A case for a monosyllabic foot: Selkirk (1978) and Bullock (1994)}

In Selkirk (1978), a simple, i. e. redundant, foot is contrasted with a derived foot. The core assumption behind a derived foot is that no syllable with a schwanucleus can constitute a foot of its own. Thus, if a nucleus contains a schwa, the syllable is combined with the syllable to the left to form a foot. A schematic representation of obligatory foot formation with corresponding examples is reproduced below. ${ }^{2}$

(2) French Foot Formation (Selkrik 1978)

a. The Simple Foot : $\mathrm{C}_{0} \mathrm{~V} \mathrm{C}_{0} \rightarrow\left(\mathrm{C}_{0} \mathrm{~V} \mathrm{C}_{0}\right)$ (mal) 'mal'

b. The Derived Foot: $\mathrm{C}_{0} \mathrm{~V} \mathrm{C}_{0} \cdot \mathrm{C}_{0}$ ə $\mathrm{C}_{0} \# \mathrm{X} \rightarrow\left(\mathrm{C}_{0} \mathrm{~V} \mathrm{C}_{0} \cdot \mathrm{C}_{0}\right.$ ə $\left.\mathrm{C}_{0}\right)$ $\mathrm{ku}$ (lœ. vrə) 'couleuvre' pro (mə. nə) 'promène'

The rightmost syllable containing the schwa is a dependent syllable: the schwa in the dependent syllable of the derived foot deletes, provided that it is separated by a single consonant from the preceding vowel, i. e. does not produce an unsyllabifiable cluster. As a result of this deletion and the subsequent closed syllable adjustment, (mə.nə) surfaces as [men]. This type of analysis allows Selkirk to state the stress rule in terms of feet: the last foot in the word is stressed (Selkirk 1978: 110). The stress is realized on the full vowel contained in the left, strong branch of the foot.

Selkirk's assumption of the monosyllabic foot is endorsed in Bullock (1994). However, for Bullock, Selkirk's dependent syllable is a degenerate foot which deletes if the onset consonant can be mapped into the previous foot.

(3) Schwa-deletion and refooting (Bullock 1994)

$(\mathrm{d}$ y) $(\mathrm{r}$ ə) $\rightarrow$ (d y) (r ə) $\rightarrow$ (d y r)

2 Selkirk (1978) originally uses tree-structure formalism for representing foot-formation, simplified here and presented as a footing algorithm. This is also done in subsequent presentations of previous work, unless noted otherwise. 
The resultant foot [dyr] obeys the canonical syllable template in Bullock's analysis: it can include a single coda consonant at most. Thus, schwa deletion is motivated by foot structure, i. e. elimination of the degenerate foot in favor of a unary foot.

In Bullock (1998), schwa-elimination is analyzed as weak-branch elimination in the binary foot, much like the earlier dependent syllable of Selkirk, in favor of a unary one. Under Bullock's analysis, schwa-final feet can resolve the degenerate nucleus via two strategies: strengthening it by turning it into a full vowel or deleting it altogether.

(4) Resolving the uneven foot (Bullock 1998)

a. Weak Branch Phonemicization:

$[\sigma \mathrm{x}]=>[\sigma \sigma]$, where the weak branch $\sigma$ is $[\varnothing]$

(for.zə)(r̃̃) $=>$ (forz $\varnothing)$ r̃

b. Weak Branch Elimination:

$$
\begin{aligned}
& {[\sigma \mathrm{x}]=>[\sigma]} \\
& \text { maiso(ne.tə) }=>\text { maiso(net) 'maisonnette' } \\
& \left(\mathrm{e} . \int \partial\right) l \tilde{\partial}=>\left(\mathrm{e} \int\right) \text { lõ 'échelon' }
\end{aligned}
$$

The surfacing of the underlying schwa as the front rounded mid-vowel, (4a), as opposed to schwa-elimination (4b), is motivated by phonotactic restrictions: the resultant three-consonant cluster is prohibited. As a result, the trochee is even and the Iambic-Trochaic Law is thus respected by the surface foot structure. This is a word-internal phenomenon. If there are no such restrictions, or when the uneven trochee is word-final, Bullock argues that French resolves the uneven trochee by eliminating the offending branch, as in (4b). The weak-branch elimination strategy applies to a significantly greater number of disyllabic lexical items, and results in a great number of monosyllabic words. It is thus this unary monosyllabic unit that constitutes the Minimal PrWd in French, according to Bullock.

\subsection{A case for a monomoraic foot: Scullen (1997)}

A robust proposal for a quantity-sensitive minimal word in French is developed in Scullen (1997) - an extensive analysis of outputs of prosodic-morphological operations in French. Based on the final-syllable distribution of tense/lax variants of mid-vowels in SF (Loi de position), Meridional French, and in Québécois, ${ }^{3}$ as well as the distribution of high vowels in Québécois, Scullen

3 See Scullen (1997: 26-37). 
posits moraic coda consonants in French. She argues that the output of truncation in French, exemplified in the formation of abbreviations, acronyms, hypocoristics etc., conforms to an iambic template, which consists of one or two of the following foot shapes: (H), (LL), and (LH).

(5) Prosodic abbreviations in French (Scullen 1997: 94)

[fakylte] $\rightarrow$ [fak] (H) 'faculté'/ 'fac'

[laboratwar] $\rightarrow$ [la.bo] (LL) 'laboratoire'/ 'labo'

[manifદstasjũ] $\rightarrow$ [ma.nif] (LH) 'manifestation'/ 'manif'

Abbreviations can also contain more than one foot, or one foot and an unfooted, light syllable: e. g. "météo" - (LL) L, and "distrib" - $(\mathrm{H})(\mathrm{H})$, respectively. For Scullen, this iambic foot and its three instantiations constitute a Minimal Prosodic Word in French. The foot proposed by Scullen is in compliance with moraic binarity. However, an important contradiction arises: a large number of lexical items in French violate the iambic minimality (examples reproduced from Scullen 1997: 102):

(6) Monomoraic violations of foot binarity

'pot' [po] container 'eau' [o] water

'loup' [lu] wolf 'rue' [ry] street

'lait' [le] milk 'feu' [fø] fire

'clé' [kle] key 'sang' [sã] blood

'rat' [ra] rat 'nom' [ñ̃] name

As Scullen correctly points out, these words cannot be considered function words, which are cross-linguistically accepted violations of word-minimality. These forms can potentially be accounted for as lexical exceptions to foot minimality (cf McCarthy et al. 1993b), with word-minimality holding for the rest of the lexical entries in a language. Alternatively, the binary word minimality can be said to be limited to truncation. Scullen, following Itô and Mester (1992), assumes that it is only lexical items derived from some prosodic-morphological processes, labeled as "p-derived words" in their work, that are subject to the binarity condition, i. e. the iambic foot is active only in prosodic-morphological operations. As such, the principle of binarity does not apply to the rest of the lexicon in French. I will then assume that vowels associated to a mora are able to constitute a sufficient rhyme for a Minimal Prosodic Word, L, in the analysis of Québécois. 


\subsection{Segmental weight in Québécois}

\subsubsection{Déchaine (1991)}

At the core of the proposal contained in Déchaine (1991) is the posited length distinction between high tense and high lax vowels. Tenseness is a derivative of length, or the number of root nodes to which the high vowel is associated. Short (lax) high vowels are mapped to a single root node, while long (tense) high vowels, to two.

(7) Representation of weight in Déchaine (1991: 110) ${ }^{4}$

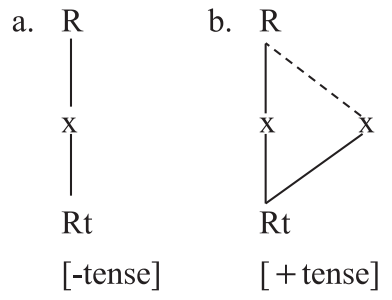

In (7a), the vowel is mapped to a single root node underlyingly, while in (7b), the vowel is mapped to two root nodes as a result of weight gain, represented by a dotted line. Weight gain is obligatory in strong rhymes, or rhymes exhaustively dominated by [s], but is optional in rhymes non-exhaustively dominated by [s]. No weight gain may take place in weak rhymes, $[w]$, under this analysis. The proposed metrical template is as follows:

(8) Metrical template (Déchaine 1991: 108)

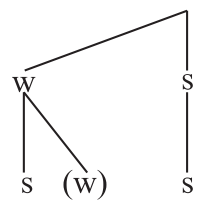

The rightmost strong rhyme, exhaustively dominated by an s-node, represents the position of primary stress. In this position, a high vowel associated to a single root node must gain weight, as shown in (7b). The leftmost strong rhyme is not exhaustively dominated by an s-node, which means that the weight gain

4 The original formalism is preserved here for the sake of an accurate exposition of the author's proposal. 
is optional, and the vowel may remain associated to a single root node, i. e. surface as lax. The vowel in the weak rhyme, i. e. the medial one, may not augment and surface as tense. Under this analysis, a word like "vie" can only surface as [vi], whereas a word like "numéro" can surface with a lax high vowel [nymero] and with a tense vowel [nymero]. However, for Déchaine, a word like "camouflage" cannot surface with a tense vowel: [kamuflaz], but *[kamuflaz], unless such a vowel is word-medial but morpheme-final. In Déchaine’s analysis, the final syllable - a rhyme exhaustively dominated by [s] - is the most prominent metrical position in the word: it is the location of primary stress where weight gain is obligatory, and no segmental weakening can take place.

For a high vowel to surface as lax, i. e. without branching the root node, the rhyme must contain an additional, distinctive root node. This root node may be occupied by a consonant:

C-final [s]-rhymes (Déchaine 1991: 110)

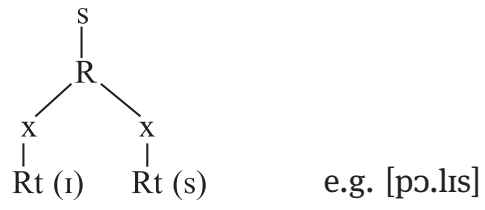

This analysis appears to imply that there is a size minimality restriction on the final metrical constituent: [s]-rhyme under [s]-node at the word level. This restriction seems to be two skeletal slots $-\mathrm{x} x$, whether under a branching root node resulting from weight gain, or from two underlying root nodes. An alternative interpretation of the minimal size imposed on the final syllables, in terms of weight units, is undertaken in Montreuil (2004a, b, 2005).

\subsubsection{Montreuil (2004a, b, 2005)}

Montreuil (2004a,b, 2005) establishes a framework in which the surface realization of high vowels is derived from syllabic weight. Montreuil's analysis is based on a proposal for a relationship between inherent segmental sonority and phonological weight, amply explored in in the literature (cf Gordon 2002b, 2004b, Morén 2003, Zec 20035). Québécois vowels are divided into three tiers

5 A direct relationship between segmental sonority and prosodic structure is explored in Zec (2003), an analysis of Mordwin. Zec finds that non-high vowels consistently receive stress, while high vowels are stressable only if no non-high vowel is available: tuc'än'ä, "cloud”, "tušðndat" “you go away”, but "kuli'ti “in that ash” (Zec 2003: 128). Zec puts forth a principle of Prosodic 
of height with corresponding degrees of sonority: high vowels (Deg1), mid vowels (Deg2), and low vowels (Deg3). ${ }^{6}$ Deg2 and Deg3 vowels are associated to $\mu$. The split between Deg1 vowels and Deg2 and Deg3 vowels is viewed as phonologically significant. To represent this distinction within Moraic Theory (Hyman 1985, Hayes 1989b), Montreuil uses a half-mora with a notation of $\gamma$ to encode the inherent weight of high vowels (Montreuil 2004a,b).

(10) Sonority-to-Weight for Québécois -- vowels

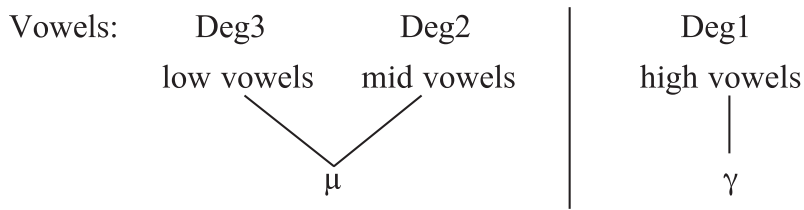

According to Montreuil, consonants are also weight-bearers in Québécois. All consonants outside the class of voiced continuants are inherently weightless, while voiced continuants are associated to the half-mora $\gamma$. This sonority distinction between voiced continuants and all other consonants is based on the fact that the former constitutes a group of lengthening consonants: high vowels preceding them surface as tense and lengthened or lax and diphthongized.

(11) Sonority-to-Weight in Québécois - consonants, as function of Degree

\begin{tabular}{|c|c|c|c|c|}
\hline Consonants: & $\begin{array}{c}\text { Deg4 } \\
+ \text { vce, + cont }\end{array}$ & $\begin{array}{c}\text { Deg3 } \\
\text {-vce, + cont }\end{array}$ & $\begin{array}{c}\text { Deg2 } \\
+ \text { vce, }- \text { cont }\end{array}$ & $\begin{array}{c}\text { Deg1 } \\
\text {-vce, - -cont }\end{array}$ \\
\hline & $\gamma$ & & 0 & \\
\hline
\end{tabular}

In coda position, consonants' inherent weight is augmented to the next weight value, contributing weight to the total weight of the rhyme - positional weight. Thus, voiced continuants become fully moraic, while all other consonants

Peak Transparency, which states that prosodic constituents higher on the hierarchy impose more restrictive sonority thresholds than those subordinated to them. As such, given the facts of Mordwin, she concludes that the Minimal Sonority Threshold imposed by the foot is [-cons, -high], while that imposed by the syllable is [-cons].

6 For an example of an analysis that relates vowel height and syllable weight, see the treatment of the diachronic change in Finnish - the analogical leveling of the genitive plural formation, in Anttila and Cho (1998). Predictably, Anttila and Cho posit a universal constraint hierarchy in which heavy syllables prefer low vowels while light syllables prefer high vowels. Their hypothesis is supported by the observation that both vowel height and syllable weight correlate with duration. 
become associated to $\gamma$. Montreuil posits a quantitative minimum for word-final syllables: they must be heavier than $\gamma$.

(12) Weight minima in high vowel surface distribution (Montreuil 2004a) a. $1 \quad i_{i}^{\mu}$ b.

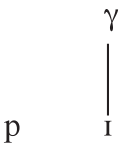

c.

$$
\left.\right|_{p} ^{\gamma}
$$

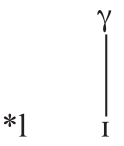

Lax high vowels, linked to a weight that is too low, are unable to constitute a PrWd on their own, illustrated in (12c). In syllables containing a coda, (12b), the minimum is achieved and the vowel surfaces as lax. In (12a), a high vowel in an open syllable meets the weight minimum via association to a full mora, which on the surface corresponds to tenseness.

To sum up, the current analysis exploits the previously explored proposals of quantity-sensitivity and the possibility of positing a branching foot to account for a series of phenomena in French. The sections that follow develop a case for a quantity-sensitive foot in Québécois, primarily motivated by the distribution of high vowels in this dialect and of critical import in analyzing the behavior of these vowels.

\section{A proposal for the monomoraic foot in Quebecois}

\subsection{High vowel moraicity: The hypomora}

Following Montreuil's work, I adopt the sonority-based weight distinction for Québécois vowels, and, in line with Scullen's view, the MinPrWd in Québécois is posited as a light syllable L. Given that high vowels are not able to constitute sufficient rhyme material, in the current proposal, they are analyzed as superlight: SL. This means that for moraic encoding, lax high vowels must be associated to weight value that is less than a mora. I propose to designate this value of fragmented weight as a hypomora, $\lambda$. This captures the key assumption from which this analysis departs: anything less than a mora is insufficient, given the minimally monomoraic prosodic requirement, thus re-interpreting for the context of Québécois, where the MinPrWd is L, the conventional view of minimality based on the principle of binarity. While a mora is traditionally viewed as the elementary, basic unit of weight in traditional Moraic Theory (esp. Hayes 
1989b) this study follows previously developed analyses of reducing a mora to a smaller unit. ${ }^{7}$

(13) Superlight, hypomoraic syllable: $\sigma_{\lambda}$

Based on Morén (2003), I assume that Québécois follows the cross-linguistic pattern of displaying two types of weight - distinctive and coerced. Distinctive weight is defined as "underlying moraicity reflected in a surface contrast", while coerced weight is defined as "a restriction on minimal or maximal surface moraicity in some phonological contexts” (Morén 2003: 284). Distinctive moraicity is said to be exemplified by underived geminates for consonants and underived vowel length for vowels. Under the current analysis, vowels are not associated to weight underlyingly - weight is assigned by the grammar based on sonority. Therefore, this is not distinctive weight, given that distinctive weight results from an interaction of markedness and faithfulness constraints. As such, the only distinctive weight in Québécois is the underlying bimoraicity of inherently long vowels: these vowels are underlyingly associated to two moras.

To formalize the proposed view of the foot in Quebecois, centered on the interplay between the underlying form and the surface form mediated by the grammar, I will make use of the Classical version of Optimality Theory (Prince and Smolensky 1993/2003/2004, Archangeli and Langendoen 1997, Kager 1997). In order to encode distinctive moraicity in OT terms, the following constraints are necessary: a familiar faithfulness constraint preserving the moraic affiliation from the input to the output form, and a markedness constraint requiring vowels to be associated to a mora. The latter constraint, adopted here following Montreuil (2004a), is essentially a counterpart to the markedness constraint

7 The most relevant one, Montreuil (2004a,b) treatment of Québécois monosyllables using a half-mora, is discussed earlier in Section 2.2. Much like the demi-beats and the demi-syllables, demi-moras have a place in phonological analysis. Abu-Abbas, Al-Kadi and Al-Tamimi (2010) in their analysis of imposition-type language games in Arabic, invoke the notion of a demi-mora. In imposition-type games, a consonant is imposed on the prosodic peak of the vowel. The point of departure is a demi-syllable (cf Fujimura 1979, Clements 1988): the first demi-syllable consisting of the onset and the vocalic peak, e.g. in the word [pi:s] "peace", [pi] while the second demi-syllable consists of the peak and the coda [iis]. Abu-Abbas, Al-Kadi and Al-Tamimi show that in Japanese, a quantity-sensitive language, the imposition occurs on every mora. For example, in the word [hai] "yes", the imposition of the consonant -b confirms to the following demi-mora structure (Abu-Abbas et al. 2010: 84):

Word Demi-moras b-imposition hai ha ai habaibi 
prohibiting long vowels, *Long V. Unlike the constraint against bimoraic vowels, although present in the grammar, the proposed constraint allows to distinguish among three types of moraic association for vowels under the current view: hypomoraic, monomoraic and bimoraic.

(14) Constraints for distinctive moraicity

FAITH- $\mu$ : The moraic association of a segment in the input is identical to that in the output. One violation per segment that fails to satisfy this condition. (After McCarthy et al. 1995a)

$\mathrm{V}-\mu$ : The moraic association of a vowel must be a single mora. One violation per vowel that is associated to something other than a single mora.

(15) Distinctive moraicity in Québécois: inherently long vowels ${ }^{8}$

f $\varepsilon_{\mu \mu} \mathrm{t}$ [f $\left.\varepsilon^{\mathrm{t}} \mathrm{t}\right]$ 'fête'

p $a_{\mu \mu} \mathrm{t}[\mathrm{pa}: \mathrm{t}]$ 'pâte'

FAITH- $\mu>>V-\mu$ : Faithfulness to input vs. Unmarked weight $\mu$

Unlike distinctive weight, coerced weight is not underlying but is a result of weight alteration due to some prosodic restrictions. Under Morén's coerced moraicity, a vowel augments in weight beyond the traditional monomoraic minimum of syllable nuclei. High vowels, under the current analysis, are assigned by the grammar a weight value that is less than one mora. However, I argue that due to prosodic pressures, high vowels may surface with a monomoraic association - coerced weight.

Morén further delineates three major patterns for coerced moraicity: "no vowels are forced to be moraic in some environment, only the more sonorous vowels are forced to be moraic in some environment, or all vowels are forced to be moraic in some environment" (Morén 2003: 286). Québécois constitutes the third pattern of coerced weight: all vowels are forced to be moraic in some environment. Namely, all vowels, including high, are coerced to be moraic when the vowel is the nucleus of a non-branching syllable in a simple foot. In OT terms, coerced moraicity is expressed in the following constraints: a constraint requiring a grammatical word to constitute a PrWd and a constraint proposed here following Montreuil (2004a), requiring that the vowel's moraic association

8 This representation is based on the representation of CVVC heavy syllables presented in Hayes (1995: 52). 
be based on its degree of sonority, i. e. for high vowels, the proper weight association is hypomoraic.

(16) Constraints for coerced moraicity

$\mathrm{GrWd}=$ PrWd: A grammatical word must be a prosodic word. One violation per output that violates this condition. (Kager 1999: 152)

SON-Weight (after Son in Montreuil 2004b): A vowel's surface weight association corresponds to its degree of sonority, i. e. mid and low vowels are monomoraic, high vowels are hypomoraic. A vowel that surfaces with an improper weight association incurs a violation.

SON-Weight, as defined above, does not militate for vowels to be associated to some weight - it assigns appropriate weight associations for vowels. This means that a vowel that has no weight does not violate SON-Weight. That vowels have weight is compelled by a different constraint (see further discussion.) As such, SON-Weight penalizes high vowels that are monomoraic, their low sonority requiring them to be associated to a hypomora. This may appear problematic for the markednes-based analysis of weight: if the unmarked association for vowels is $\mu$, then SON-Weight, a markedness constraint, calls for a marked, hypomoraic association for a subset of vowels. To clarify, in the current view, the monomoraic association is unmarked, while the hypomoraic is clearly marked (later expressed in a constraint against hypomoras, ${ }^{\star} \lambda$ ). SON-Weight serves as the means for the grammar to mediate between the two markedness statements. In other words, while monomoraic is generally unmarked, the lowsonority high vowels are unable to meet the monomoraicity criterion, referred to here as L (as discussed earlier in 2.2) and must thus be lower in weight in the present analysis. What is unmarked for high vowels is marked for non-high vowels, and vice versa.

(17) Coerced moraicity in Québécois: current proposal for high vowels

a. Grammatical weight $-\lambda$ (Inherent Markedness)

SON-Weight $\gg V-\mu$ : $\quad$ Sonority-based weight vs. Unmarked weight $i^{9}{ }_{\lambda} \rightarrow$ [I], e.g. [sit], *[li]

b. Weight imposed by Minimal PrWd (Positional Markedness)

$\mathrm{L}>$ SON-Weight $>\mathrm{V}-\mu$ :

$i_{\mu} \rightarrow$ [i], e.g. [li]

Minimal word size vs. Sonoritybased weight

9 Italics indicate lack of tenseness specification, given that under this analysis, it is assigned by the grammar. 
The view of vocalic moraicity retained here is that all vowels are weight-bearing, ${ }^{10}$ but not all vowels are moraic, if moraic is defined as being associated to exactly one mora. Long vowels are inherently bimoraic in Québécois, per distinctive weight, non-high vowels are monomoraic, and high vowels, hypomoraic grammatically, are coerced into a monomoraic surface association, per coerced weight.

To sum up in Morén's terms, who represents coerced weight with the following ranking -- *MORA[Seg1] >>BEMORAIC >`*MORA[SEG2] (Morén 2003: 290), grammatical weight assignment in Québécois can be captured as follows, with an addition of BEWEIGHT-BEARING, by analogy with BEMORAIC:

Coerced moraicity in Québécois: all vowels

\section{BEWEIGHT-BEARING $>$ *MORA[ + high] $\gg$ BEMORAIC $\gg{ }^{\star}$ MORA [-high]} where BEWEIGHT-BEARING must be defined as "All vowels must be associated to some weight."

If a high vowel is said to be weight-bearing, but less than moraic, a weight value that is less than one mora is necessitated for the analysis: to represent insufficient weight to satisfy minimal prosodic requirements, but weight

10 If a high vowel is coerced into a monomoraic association via prosodically-induced weight augmentation, under the traditional view of moraicity, it implies that the vowel in question is not associated to any weight by the grammar. As such, a possible alternative to a representation translating to less-than-a-mora would be a moraless nucleus. This type of approach to vowel reduction is found in Crosswhite (2000b), in which she proposes to account for extreme vowel reduction in Russian by positing non-moraic nuclei outside an iambic foot (Crosswhite 2000b: 116). These nuclei are contained in unfooted syllables and are thus not guaranteed to attain a minimum duration, resulting in a short, devoiced, or deleted vowel on the surface: domovoj $\rightarrow$ də $\left(\mathrm{ma}_{\mu} \cdot \mathrm{vo}_{\mu} \mathrm{j}\right)$, "house spirit" (Crosswhite 2000b: 120). In contrast, the moraic penultimate vowel inside the iamb only undergoes moderate reduction: $\mathrm{o} \rightarrow \mathrm{a}$. While positing moraless and moraic nuclei allows Crosswhite to distinguish between extreme reduction outside the foot and moderate reduction within the foot, it is not deemed here to be a viable alternative for Québécois high vowels on a number of important counts. First, under the current proposal, high vowels, both tense and lax on the surface, will be shown to be located not outside, but inside a foot, often serving as the head nucleus of the foot. In contrast, nonmoraic segments are treated as units that are prosodically invisible and do not contribute to foot construction and stress assignment (cf Cho and King 2003). Second, non-moraic segments are normally viewed as word-edge phenomena (cf Féry 2003 analysis of German word-final schwa-headed syllables and onsetless semi-syllables). High vowels in Québécois are found in a variety of positions within a word. In sum, the view of high vowel moraicity adopted here is that it is more marked for these vowels to be non-weight-bearing than to be associated to a weight value less than one mora. 
nonetheless, to motivate the presence of underweight vowel nucleus (and possible foot head) positions.

To sum up, the surface weight associations for high vowels in Québécois discussed up to this point are as follows:

(19) Surface weight associations: current proposal for Québécois

\begin{tabular}{ccc}
$\lambda$ & $\mu$ & $\mu \mu$ \\
\hline I y u & i y u & $\varepsilon: a:$ o: ${ }^{11}$ \\
high, lax, short ${ }^{12}$ & $\begin{array}{c}\text { e, J, } \propto \text {, a } \\
\text { high, tense, short } \\
\text { non-high, short }\end{array}$ & non-high, long
\end{tabular}

In order for the high vowel to be associated to $\lambda$ on the surface, the weight assigned by the grammar, (SON-Weight), must outrank the requirement for vowels to be monomoraic (V- $\mu$ ). This is demonstrated in (20) below using the forms [vi] "vie" and [vit] "vite", fast. Only vocalic weight is evaluated at this stage.

(20) SON-Weight $\gg \mathrm{V}-\mu$

$\begin{array}{lcc}\text { /vi/ } & \text { SON-Weight } & \mathrm{V}-\mu \\ \text { a. } \mathrm{VI}_{\lambda} \checkmark & & \star \\ \text { b. } \mathrm{vi}_{\mu} & \star ! & \\ \text { /vit/ } & & \\ \text { c. } \mathrm{vI}_{\lambda} \mathrm{t} \quad \checkmark & & \star \\ \text { d. } \mathrm{vi}_{\mu} \mathrm{t} & \star ! & \end{array}$

(20a) and (20c) both win in the absence of context, given that they both respect the weight association assigned by the grammar to high vowels - a hypomora. According to (20), high vowels are realized as lax regardless of the type of syllabic closure. However, high vowels in open monosyllables do not surface as lax, (20a). At this stage of the analysis, let us ensure that this condition is satisfied by invoking the positional markedness constraint cited in (16): $\mathrm{GrWd}=$ PrWd.

11 As stated earlier, tense and lengthened high vowels are not considered in this study, given that these are word-final phenomena, aside from morphological analogy: [pi:r] "pire" $=>$ [rõpi:re] (Walker 1984).

12 Short = unlengthened by VCL or not inherently long. 
(21) $\quad$ GrWd $=$ PrWd $\gg$ SON-Weight $>>$ V- $\mu$

/vi/ GrWd $=$ PrWd SON-Weight $\quad \mathrm{V}-\mu$

a. $\left(\mathrm{VI}_{\lambda}\right)$

$\star !$

$\star$

b. $\left(\mathrm{vi}_{\mu}\right) \checkmark$

In (21), the tense variant is selected: while violating the sonority-based weight assignment, it respects the higher ranked GrWd $=$ PrWd. In monosyllables that contain a coda, the high vowel surfaces as lax, i. e. with a hypomoraic association. This means that $\mathrm{GrWd}=\mathrm{PrWd}$ is satisfied. The presence of a coda, e. g. [vit], however, enables a rhyme to satisfy L, endorsing the current assumption that codas in Québécois are moraic. This is assured by the undominated Weight-byPosition constraint (Hayes 1989b):

(22) Weight-by-Position (WbyP): Coda consonants are associated to $\mu$ on the surface. One violation per coda consonant that is not projecting a mora.

(23) $\quad$ GrWd $=$ PrWd, WbyP $>>$ SON-Weight $>>$ V- $\mu$

/lit/

GrWd $=$ PrWd WbyP SON-Weight V- $\mu$
a. $\left(\mathrm{li}_{\lambda} \mathrm{t}_{\mu}\right)$
b. $\left(\mathrm{li}_{\lambda} \mathrm{t}\right)$
c. $\left(\mathrm{li}_{\mu} \mathrm{t}_{\mu}\right)$

$\star !$

The tableau shows that assuming coda moraicity leads to the satisfaction of the $\mathrm{GrWd}=$ PrWd constraint by (23a): the combined weight of the rhyme is sufficient to avoid the SON-Weight violation that would lead to a monomoraic association of the high vowel, as in (23c). When WbyP is not invoked, the minimal size constraint cannot be satisfied, as in (23b).

For the sake of simplicity and consistency with the Moraic Theory, the weight value to which a coda consonant is to be associated is $\mu$. Given that a hypomora is a construct used to represent a relational weight contrast between two sets of vowels, and not an elementary unit of weight, it is avoided in the representation of consonantal weight. Furthermore, it allows us to avoid adding two hypomoras for candidates with a hypomoraic nucleus: $l_{\lambda} t_{\lambda}$, which would force a re-conceptualization of the hypomora as a precise unit of weight, unnecessarily complicating the analysis. In the current view, a closed syllable with a lax high nucleus, structurally corresponding to (23a) on the surface, constitutes L, given that it is minimally monomoraic but is short of bimoraic to constitute $\mathrm{H}$. 


\subsection{High vowel distribution in the quantity-sensitive unary foot}

To follow the previously discussed assumptions about the French foot, this simple non-derived foot corresponds to a surface syllable. This type of foot is cross-linguistically marked: feet must be binary at the syllabic or moraic level of analysis. This means that the well-known FTBin constraint, calling for all feet to be binary, is low-ranked in French. To reflect this language-specific scenario in an OT grammar, a pair of constraints of the Alignment family must be introduced. These constraints, first proposed in McCarthy and Prince (1993a), militate for edge-alignment of prosodic constituents: ALIGN(PCat, PCat). The constraint $\operatorname{ALIGN}(F, R, \sigma, R)$ can assure that the right edge of a foot is aligned with the right edge of a syllable, while $\operatorname{ALIGN}(F, L, \sigma, L)$ serves as its left-edge counterpart. In order to achieve a monosyllabic foot, the two alignment constraints must act together on the same syllable. I propose to conjoin the two constraints into a single constraint, referring to the same syllable: ALIGN $(F, R, \sigma, R) \& \operatorname{ALIGN}(F, L, \sigma, L) .{ }^{13}$ The precise formulation is shown below in (24). Additionally, to represent the condition that the final syllable is the the head foot of the PrWd, RIGHTMOST is used. Exhaustive footing is assured by Parse- $\sigma$.

\section{(24) Constraints for monosyllabic foot in Québécois}

$\operatorname{ALIGN}(F, R, \sigma, R) \& \operatorname{ALIGN}(F, L, \sigma, L)$ : The right edge of a foot corresponds to the right edge of a syllable, the left edge of a foot must correspond to the left edge of the same syllable (based on McCarthy et al. 1993a). One violation per foot that violates this condition.

PARSE- $\sigma$ : Syllables are parsed by feet. One violation per syllable not dominated by a foot node. (Prince and Smolensky 1993/2002/2004)

RIGHTMOST (Align Hd-Ft, Right, PrWd, Right)

The head foot is rightmost in PrWd. One violation per candidate whose Head foot is not final in the word. (McCarthy et al. 1993a)

ALIGN $(F, R, \sigma, R)$ \& ALIGN $(F, L, \sigma, L)$ is a constraint specific to the French language, representing the low functionality of the metrical foot in the prosody of the language. This constraint is in competition with the binarity principle, yielding the following constraint ranking: ALIGN $(F, R, \sigma, R)$ \& ALIGN $(F, L, \sigma, L)>>$ FTBin. Let us recall that in Québécois, a simple foot is not binary: the MinPrWd is set at L in this language. All syllables are dominated by feet, via PARSE- $\sigma$.

13 This insight is contributed by Megan Crowhurst. 
Finally, the final foot, resistant to variation and weakening is the head foot (underlined) of the PrWd.

(25) $\operatorname{ALIGN}(\mathrm{F}, \mathrm{R}, \sigma, \mathrm{R}) \& \operatorname{ALIGN}(\mathrm{F}, \mathrm{L}, \sigma, \mathrm{L}),{ }^{14}$ PARSE- $\sigma>$ FTBin RIGHTMOST ALIGN PARSE- $\sigma$ FTBin
a. *pa. no. ra. (ma)
b. *(pa.no) (ra.ma)
c. (pa) (no)(ra) (ma) *!
d. (pa) (no) (ra)( $\underline{\text { ma }}) \checkmark$

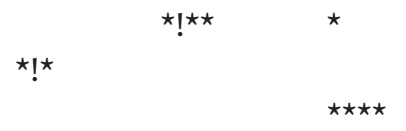

The winning candidate (25d), fully parsed with four unary feet, only violates FTBin, which is a very low ranked constraint in French. (25a) is eliminated due to an incomplete parse, (25b) due to the violation of the alignment constraint requiring a foot to be no bigger than a single syllable, (25d) has an incorrect word-level dominance structure, with the leftmost head foot.

The PrWd-level constraint GrWd $=\mathrm{PrWd}$, requiring a minimal word in French to correspond to a light syllable, applies at the level of the Prosodic Word and needs only to reference the level of the syllable - the content of the rhyme must be equal to or greater than L. Two critical facts arise that put into question the sufficiency of a minimality requirement imposed by the syllable on the one hand, and the PrWd on the other. First, word-internally, superlight rhymes are permitted: [ny.me.ro], [a.mi.tje], [di.fr.sıl]. This indicates that a purely quantitative syllable-level requirement is not sufficient to account for the insufficient size of final rhymes. Second, to satisfy the L-requirement in words longer than one syllable, the non-final syllable is not combined with the final syllable into a prosodic unit for the satisfaction of the weight requirement: $\operatorname{tr}_{\lambda}$. by $\mathrm{y}_{\mu}$, but ${ }^{\star} \operatorname{trI}_{\lambda} \cdot \mathrm{by}_{\lambda}$. This indicates that the size minimum is not imposed by the PrWd, in which case a form like $\operatorname{trI}_{\lambda} \cdot \mathrm{by}_{\lambda}$, with two hypomoraic syllables, would be perfectly grammatical. The final syllable stands out as prosodically distinct. I propose to move from the level of the syllabic rhyme to the level of the foot.

As such, the canonical foot of French is a minimally monomoraic, light syllable (L). Any monosyllable constitutes a well-formed foot. The final syllable constitutes the head foot, corresponding to the assumptions about the prominence of the final syllable in French.

Québécois foot

$\operatorname{MinPrWd}=$ Foot $\geq \mu,(\mathrm{L}),(\mathrm{H}),{ }^{\star}(\mathrm{SL})$

14 In tableaus, this constraint will be represented as ALIGN, for brevity. 
Given the current assumption about the size of the MinPrWd, the quantitative minimum at the level of the foot in Québécois is a single mora, resulting in another language-specific deviation from cross-linguistic prosodic generalizations in regards to binarity. It has already been established that FTBin, which is a constraint combining two conditions - minimal and maximal binarity - is of low functionality in the prosody of Québécois. In order to represent the proposed monomoraic minimality in this language, I propose to divorce the minimality stipulation from FTBin and set its value to a single mora.

(27) FTMin- $\mu$ : feet are minimally monomoraic. One violation per foot with the total moraic association lower than $\mu$.

Given the cross-linguistic understanding of unmarked foot structure, i. e. binary, FTMin- $\mu$ as defined in (27) appears to be calling for a marked prosodic constituent. While this is an accurate cross-linguistic insight, it must be remembered that in Québécois, the minimal word size is unary at both the syllabic and the moraic level of analysis. This means that the unary nature of the foot is sanctioned by the prosody of this language and can be viewed as unmarked in this language.

The parameters of a simple foot are analyzed in an OT tableau below. The tableau shows that foot projection is not a factor in the realization of non-high vowels.

(28) FTMin- $\mu$, ALIGN, Parse- $\sigma \gg$ FTBin : non-high vowels /pa/ FTMin- $\mu$ ALIGN Parse- $\sigma$ FTBin

a. $\left(\mathrm{pa}_{\mu}\right) \checkmark$

b. $\mathrm{pa}_{\mu}$

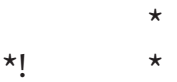

The winning candidate (28a) satisfies all the constraints except FTBin, which is very low ranked in French, as discussed previously. Monomoraic underlyingly, low vowels surface as monomoraic without the pressure exerted by FTMin- $\mu$. The picture is dramatically different for high nuclei: FTMin- $\mu$ is violated by a hypomoraic vowel, but satisfied by a monomoraic vowel, leading to a violation of SON-Weight.

When a moraic association is inserted in the input, DEP is violated. It is designated here as DEP-W(eight), to include the insertion of both $\lambda$ and $\mu$.

(29) DEP-W: every mora and hypomora has an input correspondent. One violation for each inserted weight value. 
This formulation allows us to treat a hypomora the same as a mora when possible, to minimize deviation from the traditional understanding of weight, as claimed at the outset of the hypomora proposal. Additionally, given that no segment is associated to $\lambda$ in the input, there is no need to determine what is being inserted when $\lambda$ in the input goes to $\mu$ in the output. Once again, the analysis remains consistent with the assumption that setting an exact value of $\lambda$ is an unnecessary step.

The realization of high vowels in open syllables is analyzed with the following constraint ranking:

(30) FTMin- $\mu$, PARSE- $\sigma>$ DEP-W $>>$ SON-Weight $>$ FTBin /vi/ FTMin- $\mu$ PARSE- $\sigma$ DEP-W SON-Weight FTBin
a. $\mathrm{VI}_{\lambda}$
b. $\left(\mathrm{VI}_{\lambda}\right) \quad$ !
c. $\left(\mathrm{VI}:{ }_{\lambda \lambda}\right)$
d. $\left(\mathrm{vi}^{\mathrm{j}}{ }_{\lambda \mu}\right)$
e. $\left(v i:_{\mu \mu}\right)$
f. $\left(\mathrm{vi}_{\mu}\right) \checkmark$

Candidate (30a) is not footed, and therefore cannot augment under the pressure of FTMin- $\mu$. Candidate (30b) is footed but fails to satisfy FTMin- $\mu$ with a hypomoraic vowel. Candidate (30c), (30d) and (30e) incur two violations of DEP-W. Candidate (30f) incurs only one violation of DEP-W, and is thus more harmonic with the ranking than the three previous forms. Comparing the winner with (30b), which also has only one violation of DEP-W, the tableau shows that although both candidates are equally penalized for the insertion of different moraic material -- $\mu$ vs $\lambda$, the candidate with the former satisfies FTMin- $\mu$, while the candidate with the latter fatally violates it. In other words, although DEP-W is not specific enough to distinguish between the two, it does not need to do so - the ranking of FTMin- $\mu$ > SON-Weight accomplishes this objective.

The evaluation of FTBin in the proposed hypomoraic system merits a special mention: given the goal of treating a hypomora the same as a mora when possible, a hypomora is treated equal to a mora in terms of constituting a weight value analyzed separately for the evaluation of binarity. In other words, candidates like (30c-e) are to be viewed as binary at the foot level. This being said, the low-ranking status of FTBin renders this distinction as functionally irrelevant.

For (30b) to be selected as the winner, i. e. for the high vowel to surface as hypomoraic, i.e., when both FTMin- $\mu$ and SON-Weight are satisfied, another 
rhyme constituent must contribute to the total weight of the rhyme. The grammar producing a lax vowel in a closed syllable is shown in (31):

(31) FTMin- $\mu$, WBYP, PARSE- $\sigma \gg$ DEP-W, SON-Weight $\gg$ FTBin /vit/ FTMin- $\mu$ WBYP PARSE- $\sigma$ DEP-W SON-Weight FTBin
a. $\mathrm{VI}_{\lambda} \mathrm{t}_{\mu}$
b. $\left(\mathrm{VI}_{\lambda} \mathrm{t}\right)$
c. $\left(\mathrm{VI}_{\lambda} \mathrm{t}_{\lambda}\right)$
d. $\left(\mathrm{VI}_{\lambda} \mathrm{t}_{\mu}\right) \checkmark$
e. $\left(v i_{\mu} t_{\mu}\right)$
f. $\left(v i:_{\mu \mu} t_{\mu}\right)$

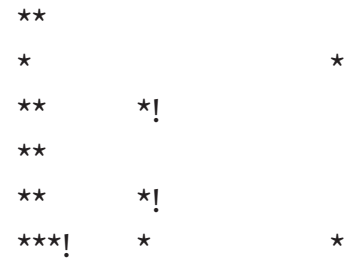

In this tableau, candidate (31d), with the hypomoraic association and in compliance with WBYP, and thus, FTMin- $\mu$, is now the winner.

In polysyllabic forms, FTMin- $\mu$ can potentially be satisfied by footing the hypomoraic rhyme with the syllable to the left.

(32) FTMin- $\mu$, ALIGN, PARSE- $\sigma>$ SON-Weight, FTBin
/ãvi/
FTMin- $\mu$ ALIGN
PARSE- $\sigma$ SON-Weight FTBin
a. $\left(\tilde{\mathrm{a}}_{\mu} \mathrm{VI}_{\lambda}\right)$
b. $\left(\tilde{a}_{\mu} v i_{\mu}\right)$
c. $\left(\tilde{a}_{\mu}\right)\left(\mathrm{vI}_{\lambda}\right) \quad$ !
d. $\left(\tilde{a}_{\mu}\right)\left(v i_{\mu}\right) \checkmark$

Candidates (32a) and (32b) satisfy foot minimality but crucially violate a highlyranked alignment constraint. Crucially, (32b) violates SON-Weight gratuitously it can satisfy FTMin- $\mu$ without violating SON-Weight. Candidate (32c) has the correct foot structure, but fails to augment to satisfy FTMin- $\mu$. Candidate (32d) is the winner: the correct foot structure motivates augmentation to satisfy FTMin- $\mu$.

The current proposal for the segmental weight in Québécois and the role of the unary foot projection in the realization of high vowels will now be extended to the non-final environment, which lends itself to a branching foot projection.

\section{High vowel distribution in the non-final environment}

\subsection{Tense-lax alternation}

In the non-final environment, the behavior of high vowels falls short of the complementary distribution in the final syllable. In the closed syllable, the 
vowel can indeed surface as lax. In fact, Déchaine (1991) goes so far as asserting that laxness is obligatory instead of optional in this environment: [kJmik|mã] “comiquement”, [anyl|mã] "annulement”, [Jatuj|mã] "chatouillement." (Déchaine 1991: 109). While Déchaine does not supply forms in which there is no possibility of a morphological boundary accounting for obligatory laxness, Walker (1984) supplies analogy-independent forms: [bul.var] "boulevard”, [vyl. ger] "vulgaire". In regards to position, the lax variant can appear in an initial or a medial closed syllable: [kõ.stryk.sjõ] “construction”, [re.pyl.siv] "répulsive”. In sum, it is sufficient for a non-final syllable to be closed in order to surface with a lax high vowel, aligning with the distribution in the final syllable, in which laxness is obligatory.

The behavior of high vowels in open syllables is considerably less systematic. The only possible source of traditionally-assumed assimilatory laxness is another high vowel - in the most straightforward cases, the obligatorily lax high vowel in the final closed syllable. Poliquin (2006) puts forth three types of harmonic assimilation of laxness: local non-iterative - [ilisit], non-local [IllisIt], and across-the-board - [IlIssIt] ("illicite"). Non-local harmony also includes cases with transparent vowels: [Inedit] "inédite”. However well-motivated for the subset of forms containing a laxness trigger, the harmony analysis runs into a problem when the trigger is not present. Two distinct configurations are analyzed: the final syllable contains a tense high vowel: (33), the final syllable does not contain a high vowel: (34).

(33) Tense high vowel in final syllable
a. missive missive
[mI.si:v]
b. fini
finished, p.p. [fr.ni]
c. toupie spinning top [tu.pi]

(34) No high vowel in final syllable

a. bouder to pout [bu.de]

b. bidon can [bI.d̃̃]

With forms such as (33a), Poliquin (2006) invokes a derivation in which Final Closed Syllable Laxing and Laxing Harmony take place before Voiced Continuant Lengthening. With forms like (33b), Dumas (1976) invokes harmony via a morphologically related form that does contain a trigger: fi.nIs "finisse", pres. subj. Forms such as (33c) are accounted for via dissimilation of tenseness (Dumas 1976: 166). For no high vowels in the final syllable, (34a) can also be treated with morphological analogy: [bu.de] [bud] ("boude", "boudes", 
"boudent”). This account, however, would have nothing to say for [bI.d̃̃], in (34b), a noun for which no morphologically-related form can supply a laxness trigger.

Québécois contains a plethora of polysyllabic words which contain only one high vowel in an open syllable, with the rest of the vowels non-high. In sum, three principal types of accounts can be extended to these forms. First, high vowels are assumed to be lax underlyingly, as in Déchaine (1991), and surface as such. Second, lax vowels are tense underlyingly, and the non-final laxness is accounted for via Open Syllable Laxing in Walker (1984). Walker, however, limits this process to initial syllables of trisyllabics only, with medial syllables accounted for by adjacent Laxing Harmony (thus requiring a morphological relationship with a form containing the appropriate trigger). Third, the lax variants in such words can simply be rejected, as in Poliquin (2006). Poliquin excludes the possibility of a lax high vowel in a pre-tonic open syllable, if there is no lax high vowel (or a high vowel) to trigger laxing by a type of harmony. Thus, /mitcn/, has only one possible realization: [mi.ten], at the exclusion of [mI.

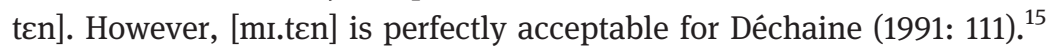

An analysis that fully accounts for the behavior of high vowels in the nonfinal environment must include all reported realizations of these vowels in a unified and systematic fashion. The same analysis must be able to treat the tense/lax alternation in both open and closed syllables, independent of the presence of a harmony trigger or a possibility of establishing morphological analogy. Crucially, forms like [mi.ten] must not only be included into the analysis but become its epicenter. I will assume that any high vowel in a nonfinal open syllable can surface as lax, as can any high vowel in a non-final closed syllable.

An important aspect of the distribution that remains to be examined is whether there is a distributional distinction to be made between initial and medial syllables. Previous studies supply contradictory evidence in this regard. Walker (1984: 57-58) states that the process of high vowel laxing is favored in initial syllables. Déchaine (1991: 107) favors the medial syllable for the lax realization: the distributional generalization she provides allows for both tense and lax variants in the initial position, and for only lax variants in the medial position, i. e. only weak vowels can appear in a metrically weak position. The

15 For an asyllabic treatment of non-final laxness, see Côté (2008). In this analysis, the possibility of a lax vowel is a function of the strength of the perceptual link that exists between the vowel and the following consonant: the stronger the link, the higher the possibility of the lax variant on the surface. Critically, it is the tenseness of the vowel that determines the syllable cut, and not vice versa. 
only instance of quantitative findings is presented in Poliquin (2006: 58-73). In his study of harmonic patterns in words in which all vowels are high, e. g. /3yridik/ "juridique", Poliquin finds that two out of 12 speakers opt for the across-the-board pattern, [3Yridik], three give higher acceptance rates to a nonlocal pattern, preferring the initial syllable, [3yridrk], and four speakers prefer the adjacent non-iterative pattern, [3yridrk]. The remaining three speakers are said to not display a distinctive pattern that can be classified. These numbers do not clearly point to one pattern being overwhelmingly more favored over others. Interestingly, however, although inconclusive, more speakers prefer the adjacent non-iterative pattern, the least marked instantiation of harmony. Dumas (1987) confirms the existence of the three patterns, but states that the preferred pattern is the alternating one, corresponding to Poliquin's non-local. These facts do not easily lend themselves to a generalization setting the medial or the initial syllable apart as a more likely host of laxness for high vowels. In light of this discussion, I will assume that all things being equal, lax variants are as plausible in medial as they are in initial positions.

(35) Tense/lax alternation in non-final open syllables: data under current view

$$
\begin{aligned}
& \text { [mi.nyt] [mi.nyt] } \\
& \text { [tu.pi] [tu.pi] } \\
& \text { [vi.tes] [vi.tes] } \\
& \text { [bu.tcj] [bu.tcj] } \\
& \text { [mi.ten] [mI.ten] } \\
& \text { [di.na.mık] [dı.na.mık] } \\
& \text { [sty.pœr] [sty.pœr] } \\
& \text { [a.mi.tje] [a.mi.tje] } \\
& \text { [3y.mel] [3Y.mel] } \\
& \text { [ny.me.ro] [ny.me.ro] } \\
& \text { [bu.de] [bu.de] } \\
& \text { [salyter] [salyter] } \\
& \text { [my.zi.sj } \tilde{\varepsilon}] \sim \text { [my.zI.sj } \tilde{\varepsilon}] \sim \text { [my.zi.sj } \tilde{\varepsilon}] \sim \text { [my.zI.sj } \tilde{\varepsilon}] \\
& \text { [difisıl }] \sim \text { [difısıl }] \sim \text { [di.fi.sıl }] \sim[\text { di.fI.sil }]^{16}
\end{aligned}
$$

\subsection{Optional deletion and devoicing}

These two phenomena share a crucial prosodic restriction: the medial syllable is by far the more frequent locus, with the initial syllable largely excluded. Deletion takes place primarily in open syllables with a simple onset, preferably also followed by a syllable with a simple onset, making re-syllabification possible. A representative data sample for devoicing and deletion in the medial syllable is presented below:

16 It must be recalled from a discussion of harmony in Chapter 1, that the study in Poliquin (2006) limits the possible realizations of "similitude"-type words to these four forms. For Poliquin, these forms mimic the harmonic patterns of tri-syllabics. 
(36) Deletion and devoicing

\begin{tabular}{|c|c|c|c|}
\hline a. Deletion & & b. Devoicing & \\
\hline [myz.kal] & musical' & 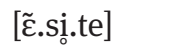 & 'inciter' \\
\hline [kom.te] & 'comité' & [de.py.te] & 'député' \\
\hline [pol.trk] & 'politique' & 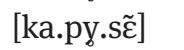 & ‘capucin' \\
\hline osp.la.sjõ] & 'population' & [de.ku.pe] & 'découper' \\
\hline ap.se] & 'tapisser' & [e.ku..te] & ‘écouter’ \\
\hline deg.ze] & 'déguiser’ & [e.ki.pe] & ‘équiper’ \\
\hline
\end{tabular}

The first study to relate the locus of deletion to abstract phonological structure is Cedergren and Simoneau (1985). For these authors, the two processes of vowel reduction - deletion and devoicing, are a result of the interaction between underlying phonological structure and phonetic surface realization (Cedergren and Simoneau 1985: 57-58). This view strongly resonates with the prosodic account proposed here - the interaction between abstract phonological structure and phonetic realization. The findings in regards to the position favoring deletion are at first glance surprising: the initial position of the rhythmic group is the most likely to host deletion of a high vowel. However, a closer look reveals a critical distinction between function and lexical words. That is, of the 18 items exemplifying syncope (Cedergren and Simoneau 1985: 70-71), ten contain an unrealized high vowel in the initial syllable, but eight of the ten are function words, for the most part not presented in isolation. Of the nine lexical items, eight contain the syncopated vowel in a medial syllable. These facts point in the direction of the validity of the generalization that deletion is largely limited to medial syllables of PrWds. Interestingly, the analysis foregoes incorporating this generalization into the proposal for prominence structure. Instead, the authors adopt the notion of the metrical grid, developed for French in Selkirk (1978). This grid is based on the prominence relationship among syllables, expressed in rhythmic beats: full vowels receive a demi-beat and a basic beat, while schwas - only a demi-beat. Cedergren and Simoneau extend this analysis to high vowels in Québécois. High vowels only receive a demi-beat, unless they are located in the last syllable of a lexical word, or in a closed syllable, in which case they are assigned a full beat. Under this view, the following rule of high vowel deletion is proposed: a high vowel deletes when it is not assigned a basic beat. A quantitative account of high vowel deletion that sheds light on the locality constraints is found in Couturier (1998), a phonetic study. In a corpus of isolated words, Couturier (1998: 159) finds that the rate of realization of high vowels under stress, i. e. the final syllable, is $100 \%$. Of the high vowels in the non-final environment, $37 \%$ are syncopated. The distribution of these vowels across the syllabic positions reveals a pattern: the higher rates of syncope vs 
retention are found in the second syllable of tri-, tetra-, and pentasyllabic words, while the rates of retention are higher in the first syllable of di-, tri-, and tetraand pentasyllabic words (Couturier 1998: 160). The clear trends revealed by these findings are as follows: 1) final syllables are completely resistant to deletion, and 2) initial syllables are strongly resistant to deletion. This provides a basis for establishing a prominence relationship for adjacent syllables, to be grouped into a branching disyllabic foot.

\subsection{A proposal for foot structure in the non-final environment}

Previous proposals for branching foot structure in Québécois include a single iamb at the right edge (Charette 1991), right-branching metrical structure at the level of the Phonological Phrase and the foot (Phinney 1980), and both iambic and trochaic feet: a left-edge trochee and a right-edge iamb (Goad and Buckley 2006). These proposals are based on the location of primary and, for some, secondary stress in Québécois. ${ }^{17}$ In the same manner, the type of foot proposed here also posits prosodic headship on the basis of the initial and final phonological prominence: foot heads are aligned with these positions. However, unlike these proposals, the present work deals with more abstract, phonological prominence rather than rhythmic stress, and the current foot proposal is more aligned with the schwa-based trochees developed in Selkirk (1978), further developed in Montreuil (1993), and Bullock (1994), discussed earlier in 2.1. As such, the grouping of the syllables into feet is independent of the location of these prominence positions. Namely, I propose to group non-final hypomoraic syllables with an adjacent syllable to form a left-dominant quantity-sensitive foot. A hypomoraic rhyme will attach itself to the syllable on the left, if available, then to the syllable on the right. The foot configuration is trochaic: the strong left branch prosodically stabilizes the high vowel in the nucleus. The weak branch corresponds to the site of weakening - devoicing and deletion of high vowels. The branching foot allows high vowels to surface as hypomoraic, i. e. lax, in both the strong and the weak branches of the foot, without resorting to obligatory weight augmentation characterizing the final syllable. The current section develops and motivates the proposed foot projection.

17 For proposals and discussions of non-primary stress in French and Québécois, see Fouché (1959), Gendron (1966), Fónagy (1979), Paradis and Dehaies (1991), Scullen (1997). 


\subsubsection{Left-edge foot $^{18}$}

Under the current view, for non-high vowels, inherently minimally monomoraic, the foot projection is redundant, given that its main function is to impose the minimum.

(37) Footing of syllables with non-high nuclei
a. $\left(\operatorname{tra}_{\mu}\right)\left(\mathrm{va}_{\mu}\right)\left(j \mathrm{je}_{\mu}\right)$
'travailler'
L L L
b. $\left(\mathrm{do}_{\mu} \mathrm{k}_{\mu}\right)\left(\mathrm{t} \mathrm{o}_{\mu}\right)\left(\mathrm{ra}_{\mu}\right)$
$\mathrm{H} \quad \mathrm{L} \quad \mathrm{L}$
'doctorat'
c. $\left(k \tilde{\partial}_{\mu}\right)\left(\operatorname{tra}_{\mu} k_{\mu}\right)\left(s j \tilde{\partial}_{\mu}\right)$
'contraction'
L $\quad \mathrm{H} \quad \mathrm{L}$
d. $\underset{\mathrm{L}}{\left(\mathrm{J}_{\mu}\right)} \underset{\mathrm{H}}{\left(\mathrm{n} \varepsilon_{\mu} \mathrm{t}_{\mu}\right)}$
'honnête'

In the examples above, open, monomoraic syllables are light, closed, bimoraic syllables are heavy. Crucially, all syllables, whether they are L or $\mathrm{H}$, bi- or trimoraic, are equivalent for assigning a foot projection: each syllable $\sigma$ corresponds to a well-formed foot.

The tableau in (38) illustrates the constraint ranking that yields the canonical foot structure posited here for Québécois: a maximally monosyllabic, minimally monomoraic foot.

(38) All syllables are minimally monomoraic and maximally monosyllabic:

FTMin- $\mu$, ALIGN, PARSE- $\sigma>$ FTBin

$/ \sigma \sigma \sigma / /^{19}$

FTMin $-\mu$ ALIGN PARSE- $\sigma$ FTBin
a. $\sigma \sigma \sigma$
b. $(\sigma \sigma)(\sigma)$
c. $(\sigma)(\sigma \sigma)$
d. $(\sigma \quad \sigma \quad \sigma)$
e. $(\sigma)(\sigma)(\sigma) \checkmark$

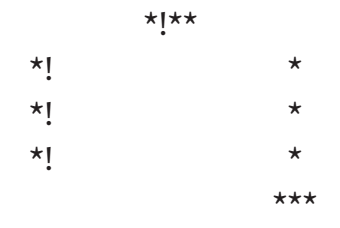

All the constraints to the left of the crucial ranking are satisfied by the winning candidate (38e). Candidates (38b-d) violate the highly ranked Alignment

18 This analysis considers di-syllabic and tri-syllabic forms, which comprise the majority of the lexicon. For the extension of this analysis to tetra- and penta- syllabic words, see Bosworth (2011).

19 A minimally moraic syllable (open or closed), is represented with $\sigma$, while $\lambda$ stands for a syllable with a hypomoraic rhyme. 
conjunction ALIGN - the polysyllabic foot edges are not aligned with the respective edges of the same syllable. Candidate (38a) is eliminated due to the absence of a foot projection. FTMin- $\mu$ is an inactive constraint for candidates containing minimally monomoraic rhymes.

Following the standard assumption that every foot must have a head (cf Hayes 1995), the only syllables of the monosyllabic feet in the winning candidate (38e) are foot heads. FT-to-Head is incorporated into the ranking to produce monosyllabic, monomoraic feet that all have heads. Additionally, let us recall that the final foot is the head foot of the PrWd, expressed via RIGHTMOST:

(39) All monosyllabic, minimally monomoraic feet have a head, $\underline{\sigma}$; the final foot is the head of the PrWd, ():

RIGHTMOST, FTMin- $\mu$, ALIGN, PARSE- $\sigma$, FT-to-Head $>$ FTBin

$/ \sigma \sigma \sigma /$

RIGHT FTMin- $\mu$ ALIGN PARSE- $\sigma$ FT-to- FTBin MOST
a. $(\sigma)(\sigma)(\underline{\sigma})$
b. $(\underline{\sigma})(\sigma)(\underline{\sigma})$
c. $\quad \sigma \quad \sigma \quad(\underline{\sigma})$
d. $(\underline{\sigma})(\underline{\sigma})(\underline{\sigma}) \checkmark$

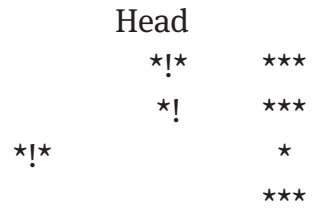

Candidate (39a) has only one headed foot - the head of the PrWd, and thus incurs two violation marks. Candidate (39b) has two headed feet: each aligned with a PrWd edge, with the headless medial foot causing the candidate to incur a violation mark. Candidate (39c) satisfies FT-to-Head, but at the expense of containing unfooted syllables: Parse- $\sigma$ is undominated in French due to the exhaustive footing posited under the current analysis. Candidate (39d) has three feet and three foot heads, and is thus selected as the winner.

The syllable considered in the above tableaus is minimally monomoraic: this means that its rhyme exceeds a hypomora, or is heavier than SL. Hypomoraic high vowel rhymes are not able to host a licit foot projection. If each syllable is footed on its own, per ALIGN, the syllable with a hypomoraic rhyme is an $\{\mathrm{SL}\}$ foot. In trisyllabic forms, this would lead to the following foot structure:

(40) Footing of open syllables with high nuclei: alternative not retained

a. $\left\{n y_{\lambda}\right\} \quad\left(m_{\mu}\right)\left(\mathrm{ro}_{\mu}\right)$

SL $L \quad L$

b. $\left(\mathrm{a}_{\mu}\right)\left\{\mathrm{mi}_{\lambda}\right\} \quad\left(\mathrm{tje} \mathrm{e}_{\mu}\right)$

L SL L 

c. $\left\{\mathrm{sy}_{\lambda}\right\} \quad\left(\mathrm{po}_{\mu} \mathrm{r}_{\mu}\right)\left(\mathrm{te}_{\mu}\right) \quad$ 'supporter'
SL $\quad \mathrm{H} \quad \mathrm{L}$
d. $\left(\mathrm{ba}_{\mu} \mathrm{l}_{\mu}\right)\left\{\mathrm{by}_{\lambda}\right\} \quad\left(\mathrm{sje}_{\mu}\right) \quad$ 'balbutier'
$\mathrm{H} \quad \mathrm{SL} \quad \mathrm{L}$

The foot structure that maps a foot to a single syllable yields $\{\mathrm{SL}\}$ feet that do not meet the monomoraic minimality requirement. Since the final foot must be footed on its own, the only grouping alternative is to attach the hypomoraic rhyme to another syllable, thus forming a branching constituent that satisfies the monomoraic minimality requirement.

(41) Footing of open syllables with high nuclei

a. $\left(n y_{\lambda} \cdot \mathrm{me}_{\mu}\right)\left(\mathrm{ro}_{\mu}\right)$

SL L L

b. $\left(\mathrm{a}_{\mu} \cdot \mathrm{mi} \mathrm{\lambda}_{\lambda}\right)\left(\mathrm{tje}_{\mu}\right)$

L SL $\quad \mathrm{H}$

c. $\left(s y_{\lambda} \cdot \mathrm{pJ}_{\mu} \mathrm{r}_{\mu}\right)\left(\mathrm{te}_{\mu}\right)$

SL $\quad \mathrm{H} \quad \mathrm{L}$

d. $\left(b_{\mu} l_{\mu} \cdot b y_{\lambda}\right)\left(s e_{\mu}\right)$

$\mathrm{H} \quad \mathrm{SL} \quad \mathrm{L}$

This foot structure satisfies the critical foot minimality requirement. This means that the principle of foot-to-syllable equivalence is violated in favor of satisfying foot minimality. Thus, branching feet are allowed in Québécois when one of the branches contains a hypomoraic rhyme. This approach is not without precedent in French. Selkirk (1978), which also posits that a simple foot is coextensive with a syllable, combines a deficient syllable containing a schwa with a full syllable to the right: (sa.mə) (di) "samedi". The resultant left-dominant foot loses the deficient vowel in the weak branch: [sam.di]. This is analogous to high vowel deletion in medial open syllables. Unlike in the analysis of the schwa, in trisyllabic words, high vowels can attach themselves to either a syllable on the right or a syllable on the left, whichever is available. The initial syllable, corresponding to a strong phonological position, constitutes the strong branch of the foot. The right branch, the locus of weakening in trisyllables, is the weak branch. An illustration is provided below:

(42) Hypomoraic nuclei in branching rhymes

$\begin{array}{lll}\left(\underline{\mathrm{a}_{\mu}}\right. & \mathrm{mi} & \left(\mathrm{tj}_{\mu}\right) \\ \text { s-branch } & \mathrm{w} \text {-branch } & \text { s-branch (and only branch) } \\ \text { Foot head } & \text { Foot head }\end{array}$


High vowels that are subject to devoicing and deletion are mapped to the weak branch of a strong foot. This structure allows us to distinguish between the behavior of high vowels in open and in closed syllables with respect to these two processes. A high vowel in an open syllable that follows the initial syllable, given the hypomoraic status of the rhyme, always finds itself in the weak branch of a strong foot, as shown above.

Under the current analysis, the foot minimality requirement is satisfied by grouping the hypomoraic syllable with another syllable, thus extending the foot from a single syllable to two syllables. An alternative to violating the foot-tosyllable equivalence principle may be to augment the vowel to satisfy foot minimality: $\left\{\mathrm{V}_{\lambda}\right\} \rightarrow\left(\mathrm{V}_{\mu}\right)$. The high vowel then surfaces as tense, which is the more common realization in an open syllable. The problem with this type of analysis is that it fails to account for the possibility of both realizations of high vowels - the hypomoraic, lax, and the monomoraic, tense - under the same foot structure. In order for the high vowel to surface as lax, either a degenerate foot must be posited, which violates the foot minimality condition, or the syllable is to be left unfooted. Both solutions have significant disadvantages to the one proposed here.

(43) To branch or not to branch? Rejected non-branching footing alternatives
a. (a) $m i_{\lambda}$ (tje)
$\mathrm{n} y_{\lambda}$ (me) (ro)
b. (a) $\left\{\mathrm{mi}{ }_{\lambda}\right\}$ (tje)
$\left\{\mathrm{n} y_{\lambda}\right\}$ (me) (ro)
c. (a) $(\mathrm{mi} \mu)(\mathrm{tje})$
$\left(\mathrm{n} y_{\mu}\right)(\mathrm{me})(\mathrm{ro})$

In the forms in (43a), the syllable with a high nucleus is unfooted. With respect to deletion, the unfooted syllable may lose its nucleus, which works for the form with a high nucleus in the medial syllable, but contradicts the distributional facts for the form with a high nucleus in the initial syllable. It would present an analogous problem for protecting the initial syllable from devoicing. Without FTMin- $\mu$ exerting the pressure to augment the weight of the vowel, the vowel cannot surface as tense, since SON-Weight outranks the markedness condition for all vowels to be monomoraic, $\mathrm{V}-\mu$. The form containing a degenerate foot, in (43b), resolves the issue with devoicing and deletion for forms like $\{n y\}(m e)(r o)$, by protecting the vowel from deletion. Tenseness can be obtained from a foot optimization-type process: a degenerate foot is promoted to a well-formed foot in compliance with FTMin- $\mu$, resulting in (43c). The problem with this footing analysis is the positing of degenerate feet when they can be avoided. In disyllabic words, however, degenerate feet cannot be avoided.

(44) Footing of disyllabic words
a. $\left\{\mathrm{p} y_{\lambda}\right\}(n i)$
$\left\{m i_{\lambda}\right\}$ (tcn)
b. $\left(p y_{\mu}\right)(n i)$
$\left(m i_{\mu}\right)(\mathrm{tcn})$ 
The initial syllable in the forms in (44a) is a degenerate foot, containing a lax vowel. In the forms in (44b), the foot is well-formed, satisfying FTMin- $\mu$ with a monomoraic vowel. While this solution relies on different footing to obtain the two variants in this position, it cannot be avoided in disyllables. In sum, positing degenerate feet for disyllables: 1) is necessary to protect the vowel in the initial syllable and 2) is the only footing alternative for a hypomoraic rhyme.

In trisyllables, as shown earlier, the degenerate foot can be easily avoided by constructing a branching foot. The tableau in (45) below analyzes the branching foot in trimoraic syllables in an OT tableau: an unfooted syllable is disallowed, as is a degenerate foot when it can be avoided. Thus, PARSE- $\sigma$ is undominated, as is FTMin- $\mu$. Furthermore, let us recall that based on the current assumptions regarding the prosodic status of the final syllable, discussed in earlier in 3.2, the medial syllable does not combine with the final syllable. This condition can be realized via the satisfaction of two constraints: TROCHEE and a constraint aligning the head syllable of the head foot of the PrWd with the right edge of the PrWd, both introduced in (45).

(45) TROCHEE: feet are L-dominant. One violation per R-dominant foot. (Prince and Smolensky 1993/2002/2004)

ALIGN (Heado/Head F,R): The head syllable of the head foot of the PrWd stands at the right edge of the Prosodic Word (based on Generalized Alignment constraints, McCarthy et al. 1993a)

(46) Left-edge branching foot in trisyllabic words:

ALIGN (Head $\sigma /$ HeadF,R), TROCHEE, PARSE- $\sigma$, FTMin- $\mu>$ ALIGN

$/ \sigma \lambda \sigma / \quad$ ALIGN TROCHEE PARSE- $\sigma$ FTMin- $\mu$ ALIGN (Heado/HeadF,R)
a. $(\underline{\sigma}) \lambda(\underline{\boldsymbol{\sigma}})$
b. $(\underline{\sigma})\{\lambda\}(\underline{\sigma})$
c. $(\underline{\sigma})(\lambda \underline{\sigma})$
d. $(\underline{\sigma})(\underline{\lambda} \sigma)$
e. $(\underline{\sigma} \lambda)(\underline{\sigma}) \checkmark$

$\star !$

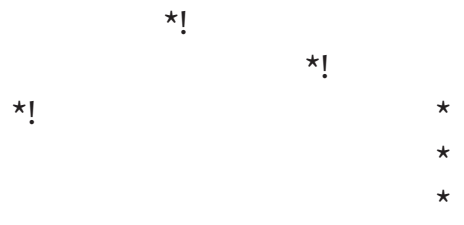

Candidates $(46 \mathrm{a}, \mathrm{b})$ are eliminated for the presence of an unparsed syllable and a degenerate foot, respectively. Candidates (46c) and (46d) both contain a branching final foot: (46c) has an incorrect headship structure and is eliminated by TROCHEE. The selection between (46d) and (46e) is made by the satisfaction of both ALIGN(Heado/HeadF,R) and TROCHEE by candidate (46e). 
When the $\lambda$-rhyme is initial, there seems to be a contradiction between the weight association of such a rhyme and the prosodic headship of the foot: hypomoras should be excluded from head positions. ${ }^{20}$ This condition is expressed in the constraint introduced in 63.

(47) ${ }^{\star} \lambda$ (Head): rhymes associated to prosodic head positions should not be hypomoraic. One violation per hypomoraic rhyme in the foot head position.

In Québécois, hypomoras are allowed in head positions. The left-branch of the left-edge foot is the head of the foot.

(48) Initial hypomoraic rhymes in branching left-edge foot

$\left(\underline{n y} \underline{\underline{\lambda}} . \quad \mathrm{me}_{\mu}\right) \quad\left(\underline{\mathrm{ro}}_{\underline{\mu}}\right)$

s-branch w-branch s-branch (and only branch)

Foot head Foot head

In the OT grammar, this means that the requirement for the foot to have a head outranks the prohibition of hypomoraic rhymes in a strong prosodic position: FT-to-Head $\gg{ }^{\star} \lambda($ Head $)$.

(49) Hypomoraic rhymes can be heads:

FT-to-Head $>>$ ALIGN (Head $\sigma /$ HeadF,R), TROCHEE $>>$ : ${ }^{\star} \lambda($ Head), ALIGN

$/ \sigma \lambda \sigma / \quad$ FT-to-Head ALIGN TRO ${ }^{\star} \lambda($ Head) ALIGN
a. $(\lambda \sigma)(\underline{\sigma})$
$\star !$
b. $(\underline{\lambda} \sigma)(\underline{\sigma}) \checkmark$

The foot structure of the winning candidate in (49) assures the absence of weakening in the initial syllable via the head status of the left branch of the foot.

In disyllabic forms, when the initial syllabic rhyme is hypomoraic, a branching foot is not a possible structure, given the prohibition against branching in the final foot. A candidate with an initial degenerate foot must be selected as the winner. Normally, for degenerate feet to be possible, the constraint regulating foot minimality must be sacrificed to the requirement for exhaustive parsing. In the current analysis of Québécois prosody, this means that PARSE- $\sigma \gg$ FTMin- $\mu$. The selection of the candidate with a hypomoraic foot, (50) is illustrated below.

20 Per Weight-to-Stress. 
(50) Degenerate hypomoraic feet in disyllabic words:

FT-to-Head, ALIGN(Head $\sigma /$ HeadF,R), PARSE- $\sigma$ > FTMin- $\mu$ > ALIGN

$\begin{array}{lll}\lambda \sigma / & \text { FT-to-Head ALIGN PARSE- } \sigma \text { FTMin- } \mu \text { ALIGN } \\ & (\text { Head } \sigma / \text { HeadF,R }) & \end{array}$
a. $\lambda(\underline{\sigma})$
b. $\{\lambda\}(\underline{\sigma})$
c. $\{\underline{\lambda}\}(\underline{\sigma}) \sqrt{ }$

It has now been established that the phonological grouping of a hypomoraic rhyme with another syllable can result in a foot with a hypomoraic rhyme in either branch of the trochee. It can also result in two consecutive hypomoraic rhymes footed together, ${ }^{21}$ constituting a foot in compliance with FTMin- $\mu$.

(51) Footing of hypomoraic rhymes
a. $(\underline{\sigma} \lambda)(\underline{\sigma})$ /amitje/
b. $(\underline{\lambda} \sigma)(\underline{\sigma}) /$ nymero/
c. $(\underline{\lambda} \lambda)(\underline{\sigma}) /$ difisil/

The form in (51c) contains two consecutive hypomoraic rhymes, whose combined weight satisfies FTMin- $\mu$, since it exceeds a single hypomora.

Given the prominence structure posited for the left-edge foot, I will refer to this left-dominant, quantity-sensitive foot as a moraic trochee. The traditional definition of a moraic trochee (cf Hayes 1995: 69) maintains that this type of foot has the following instantiations: two light syllables ( $\underline{L} \mathrm{~L}$ ) or one heavy syllable $(\underline{\mathrm{H}})$, of which the first mora is stronger. For Québécois, these trochaic configurations do not account for two important prosodic features of Québécois: hypomoraic rhymes and the size of the MinPrWd - (L). Thus, the Hayesian moraic trochee must be minimally supplemented and amended for a prosodic analysis of Québécois. In light of the earlier discussions of the size of the MinPrWd and the foot-to-syllable coextensiveness that generally characterizes this language, I posit (L) as a well-formed moraic trochee in Québécois. Feet consisting of two syllables must include a hypomoraic, SL-syllable in either or both branches, resulting into the following prosodic configurations:

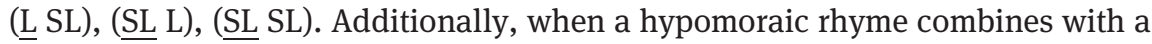

21 A parallel can be established between the grouping of two hypomoraic rhymes and the grouping of two deficient schwa-syllables, proposed as an extension of Selkirk's original foot in Montreuil (1993). In this trochee, the surface realizations of the schwa are determined by the status of the branch and the foot in which the given schwa is located. 
heavy syllable, the following configurations ensue: (ㅂ SL) (SL H). More foot shapes occur on the surface: ( $\underline{L} \mathrm{~L}),(\underline{\mathrm{H}} \mathrm{L})$, and $(\underline{\mathrm{L}} \mathrm{H})$. These shapes are derived: they result from weight augmentation into which a high vowel may be forced by prosodic pressures.

It is clear that this trochaic inventory diverges from the traditional understanding of a trochee. The innovation of this proposal consists in the following: instead of prohibiting feet that violate the trochaic structure, they are demoted to a lower point in the hierarchy. Although the Iambic-Trochaic Law is not a violable condition, it must be kept in mind that this Québécois trochee is not a metrical constituent regulating stress assignment. An approach in which two sets of constraint rankings, accounting independently for syllable-grouping and head assignment, allows for this type of analysis. The various foot shapes resulting from grouping adjacent non-final syllables into feet, including the degenerate feet in disyllables, account for the possible realizations of high vowels in a given context. However, not all generated trochee instantiations are equally well-formed. In other words, some instantiations of the Québécois foot posited above are less marked than others. The following section develops a proposal for a Trochaic Markedness Hierarchy in Québécois, which, under the current analysis, determines the nature of surface alternation of high vowels in a given prosodic context.

\subsubsection{Trochaic markedness hierarchy}

The Trochaic Markedness Hierarchy posited in this work is based on three main familiar and uncontroversial principles. The primary principle on which their relative markedness is based is quantitative minimum- $R$, crucially, at the level of the rhyme: hypomoraic, SL-rhymes are the most marked. This means that any foot containing an SL-branch would be less well-formed than the foot containing only L- or H-branches: ( $\underline{H}),(\underline{L}),(\underline{L} \mathrm{~L}),(\underline{\mathrm{L}} \mathrm{H}),(\underline{\mathrm{H}} \mathrm{L}) \gg$ (L SL), (SL L), ( $\underline{\mathrm{H}} \mathrm{SL}),(\underline{\mathrm{SL}} \mathrm{H})$, (SL SL). The second criterion is to be based on the main principle behind the traditional moraic trochee: the two branches are of equal duration, or of equal phonological weight - quantitative evenness. Two foot shapes satisfy this condition: ( $\underline{L}$ L) and (SL SL). Finally, the strong branch must be of equal or greater quantity than the weak branch - quantitative dominance. This criterion is satisfied by all shapes except ( $\underline{\mathrm{L}} \mathrm{H}),(\underline{\mathrm{SL}} \mathrm{L})$, and $(\underline{\mathrm{SL}} \mathrm{H})$. In order to posit a prosodic markedness hierarchy for foot instantiations with meaningful divisions, the three principles must be ranked with respect to one another. A violation of a higher-ranked principle is penalized more than a violation of a higher number of constraints, as in a regular OT-tableau. A partial illustration is provided below in (52), including only hypomoraic or monomoraic rhymes, i.e. pre-dominantly open syllables. 
(52) Trochaic Markedness I

(L)

(SL SL)

Q-Minimum-R Q-Evenness Q-dominance

The table shows that $(\underline{L})$ and $(\underline{L} \mathrm{~L})$ feet are the most well-formed and are equally well-formed with respect to one another. This is consistent with the current assumption that $(\underline{\mathrm{L}})$ is the basic foot of French. These two structures are never in competition. The foot ( $\underline{\mathrm{L}})$ is a foot projected by an open syllable with a nonhigh nucleus or a closed syllable with a high nucleus. The foot (L L) is a derived foot: it results from weight augmentation in either branch of a foot built on a monomoraic and a hypomoraic rhyme. It can also result from weight augmentation in both branches of a foot projected by two consecutive hypomoraic rhymes: $(\underline{\mathrm{SL}} \mathrm{SL}) \rightarrow(\underline{\mathrm{L}} \mathrm{L})$

When a non-high vowel-headed syllable combines with a high vowel on the right, (L SL) results, the opposite produces (SL L). While the table clearly indicates that $(\underline{\mathrm{L}} \mathrm{SL}) \gg(\underline{\mathrm{S}} \mathrm{L})$, this condition is irrelevant for such forms, because relative markedness is only relevant when two possible instantiations of the same form are considered. However, each of the two shapes is less wellformed than (L L).
$(\underline{\mathrm{L}} \mathrm{L})>>(\underline{\mathrm{L}} \mathrm{SL}),(\underline{\mathrm{L}} \mathrm{L})>(\underline{\mathrm{SL}} \mathrm{L})$
a. (ny.me) (ro) $>>$ (ny.me) (ro) (L L) $>$ ( $\underline{\text { SL L }) ~}$
b. (a.mi) (tje) $\gg$ (a.mi) (tje)
$(\underline{\mathrm{L}} \mathrm{L})>(\underline{\mathrm{L}} \mathrm{SL})$

Critically, the markedness prediction made by this analysis is consistent with the distributional generalizations adopted here. Namely, the least marked prosodic shape ( $\underline{L} \mathrm{~L})$ corresponds to the least marked realization: in the high vowels in non-final open syllables are more likely to surface as tense, particularly in cases where no harmonic influence can be exerted, as in examples in (53). As to the relative ranking of the prosodic shapes (SL L) and (L SL), trochaic markedness yields (L SL) as a better-formed shape, based on quantitative dominance - the only condition violated by (SL L) that (L SL) satisfies. This seems to imply that a candidate like (a.mI)(tje) is better-formed than a candidate like (ny.me)(ro), because the hypomoraic vowel in the latter finds itself in the strong branch. A confirmation of this prediction is found in Déchaine (1991), who excludes tense 
high vowels from medial open syllables, unless a morphological boundary can be established. Under this view, the proposed hierarchy does yield the (SL L) candidate as the least well-formed of all, and certainly less well-formed than ( $\underline{\mathrm{L}}$ SL). However, this incorrectly excludes ( $\underline{L}$ L), the least marked prosodic shape. Given no other confirmation of this generalization in the literature, I leave the question of distinguishing between the initial and the medial position as a locus of laxness in these types of forms open.

In sum, to account for open-syllable tenseness in trisyllabic forms, trochaic markedness correctly indentifies ( $\underline{L} \mathrm{~L}$ ) as the best formed candidate, followed by (L SL) and (SL L), whose internal ranking is not consequential to account for attested realizations of forms like [nymero] and [amitje], respectively. Given limited support in the literature, the predicted by the TMH preponderance of forms with a medial lax vowel awaits further evidence, which is partially found in words with consecutive non-final high nuclei.

The relative well-formedness of ( $\underline{L} \mathrm{SL})$ and (SL L) is, however, of significance for forms containing consecutive high vowels. More specifically, a relative order of ( $\underline{\mathrm{L}} \mathrm{SL}),(\underline{\mathrm{SL}} \mathrm{SL}), \underline{\mathrm{SL}} \mathrm{SL}$ ) is of essence for surface predictions for forms containing consecutive high nuclei.

(54) Forms with two consecutive hypomoraic rhymes

[difisıl] $\sim$ [difisıl] $\sim$ [dI.fi.sil] $\sim$ [dI.fI.sıl]

L L L SL SL L SL SL

As pointed out above, the prosodic analysis developed here predicts the order of markedness shown in (54): both vowels realized as tense are preferred, a lax vowel in the medial syllable is preferred over a lax vowel in the initial syllable, with both lax vowels as the least preferred variant. Crucially, this prediction is aligned with the quantitative results of the study in Poliquin (2006) - the only quantitative data available, discussed and referred to earlier on multiple occasions. The existing datasets referred to in this paper confirm that $(\underline{L} \mathrm{~L})$ is the most well-formed. Additionally, the metrical analysis in Déchaine (1991) predicts tense-lax and lax-lax as the two possible realizations, with medial high vowels only realized as short, thus demoting the ( $\underline{\mathrm{SL}} \mathrm{L})$ and $(\underline{\mathrm{L}} \mathrm{L})$ candidates to the end of the hierarchy. This being said, Déchaine, aligned with Poliquin, acknowledges the existence of all four instantiations shown in (54), and attributes the presence of a tense vowel in a medial syllable to the adjacency of a fricative (Déchaine 1991: 114). In sum, the only set of quantitative findings confirms the current prosodic analysis, with a sole exception of the impossibility of tense vowels in medial rhymes, not resonating with any other data reports in the literature. 
Dumas (1981: 24) cites the alternating pattern, i. e. (SL L), as prevalent, precisely due to alternation. This clearly goes against the prediction made in this analysis, correctly favoring (SL L) over (SL SL), but incorrectly favoring (SL L) over (L SL). It is likely that the notion of a tenseness contour might prove of relevance here, consistent with Dumas' analysis of forms like [lu.lu] "Loulou", based on dissimilative harmony (see Bosworth 2011). Thus, the resultant alternation is not yielded by prosody, but by the interaction of adjacent autosegmental features, [+tense] and [-tense], along with prosodic considerations already present in the grammar. This type of analysis is limited to high vowels: neither mid nor low vowels are subject to this type of alternating behavior.

The foot $\{\mathrm{SL}\}$, not included in (52), is the least well-formed and would find its place at the bottom of the hierarchy. Although this degenerate foot is more harmonic with the three criteria of trochaic markedness than (SL SL), it is not a licit foot as are all other shapes: it violates quantitative minimum at the level of the foot.

In disyllabics, the following condition is posited: $(\mathrm{L})>\{\mathrm{SL}\}$. For a form like /mitcn/, the more common realization is with a tense vowel. In the spirit of Weak-branch Phonemicization in Bullock (1998), which stabilizes an underlying schwa in the right branch, discussed earlier in 2.1, I propose that the tense vowel results from weight augmentation induced by the foot minimality requirement, resulting in a licit foot (L).

(55) Weight augmentation in a degenerate foot

(L) $\gg\{$ SL $\}$

(mi) $(\mathrm{tcn})>\{\mathrm{mI}\}(\mathrm{t \varepsilon n})$

For branching rhymes, Trochaic Markedness must be extended to include the $(\mathrm{H})$-foot, representing closed syllables with monomoraic nuclei, the (H SL) and (SL H)-feet, resulting from a combination of a hypomoraic rhyme and a closed syllable, and the two foot-forms derived from them via weight augmentation: (마 L) and (L H).

(56) Trochaic Markedness II

Q-Minimum-R Q-Evenness Q-dominance

(L H)

(․ㅡ SL)

$(\overline{\mathrm{SL}} \mathrm{H})$
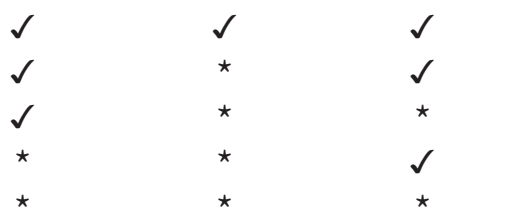
The foot form $(\underline{\mathrm{H}})$, alongside $(\underline{\mathrm{L}})$, satisfies all three trochaic markedness criteria. Per proposed Trochaic Markedness, $(\underline{\mathrm{L}})$ feet are preferred to (SL L) and (L SL). Likewise, ( $\underline{\mathrm{H}}$ ) is preferred to feet containing a hypomoraic rhyme. In line with the Weak-branch Elimination proposed for French in Bullock (1998) deleting an underlying schwa, discussed earlier in 2.1, the hypomoraic vowel in the weak branch deletes.

(57) (ㅂ)-induced deletion

$$
\begin{aligned}
& \text { (ka.mi) (zol), (kam) (zol) >> (ka.mi) (zol) } \\
& \text { (L L), } \quad(\underline{\mathrm{H}}) \quad>(\underline{\mathrm{L}} \mathrm{SL})^{22}
\end{aligned}
$$

In (56), ( $\mathrm{L} \mathrm{L}$ ) and (H) are presented as prosodically equivalent, per proposed Trochaic Markedness. The logical question that necessarily follows is whether (ka.mi) (zol) and (kam) (zol) are distributional equals. It stands to reason that a form with an unrealized segment must necessarily be viewed as inferior by the grammar. For example, one approach would be to represent the competition between the two forms as stylistic variation, which can be very neatly formalized in OT, introducing a condition that prohibits vowel deletion to satisfy TMH:

(58) High register: Max-V $\gg$ Trochaic Markedness

Low register: Trochaic Markedness $>>$ Max-V

However, modifying the proposed Trochaic Markedness itself is unnecessary and contradictory to the facts of French, in which, as discussed before, monosyllabic words of the type (L) coexist alongside the their (H)-type homologues.

(59) Alternative not retained:

$$
(\underline{\mathrm{L}} \mathrm{L}),(\mathrm{L}) \gg(\mathrm{H})
$$

When a hypomoraic branch combines with a closed syllable, the well-formed $(\underline{\mathrm{L}} \mathrm{L})$ is not a possible prosodic target, given that one of the branches is $(\underline{\mathrm{H}})$. Given that a sequence of two $\mathrm{H}$-syllables will have these syllables footed on their own, the quantitative evenness cannot be satisfied by either of the

22 Similarly, if deletion takes place in an initial syllable, which is a less frequent occurrence, the surface prosodic form is either $(\mathrm{L})$ or $(\mathrm{H})$, a result that is consistent with TMH. This is also aligned with the fact that deletion does not normally apply to non-high vowels, viewed here as being due to the fact that there is no prosodic pressure to improve an already well-formed (L) shaped of the foot containing a non-high, non SL head. 
alternating trochaic shapes when a closed syllable is involved. However, relative evenness can be established: while both $(\underline{\mathrm{H}} \mathrm{L})$ and $(\underline{\mathrm{H}} \mathrm{SL})$ are compliant with the strong-weak condition, $(\underline{H} \mathrm{~L})$ is more even that $(\underline{\mathrm{H}} \mathrm{SL})$, the latter penalized for containing an SL-branch. This means that a form like [bal.by.sje] is better-formed than a form like [bal.by.sje]. The same is true for the reversed configuration. Both ( $\mathrm{L} \mathrm{H}$ ) and (SL H) violate both quantitative evenness and quantitative dominance, but $(\mathrm{L} \mathrm{H})$ is more even than $(\mathrm{SL} \mathrm{H})$ : [sy.por.te]. > [sy.por.te]. However, no evidence is available on the surface to rank ( $\underline{\mathrm{H}} \mathrm{L})$ over (L H), or ( $\underline{H}$ SL) over (SL H). In other words, a form like [bal.by.sje] cannot be considered more well-formed than a form like [sy.por.te]. In sum, the meaningful, surface-relevant rankings of branching feet for Trochaic Markedness that includes H-rhymes are as follows:

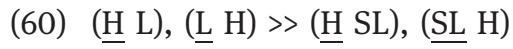

a. [bal.by.sje] $>$ [bal.by.sje] $(\underline{\mathrm{H}} \mathrm{L})>(\underline{\mathrm{H} \mathrm{SL}})$

b. [sy.por.te] $>$ [sy.por.te] $(\underline{\mathrm{L}} \mathrm{H})>(\underline{\mathrm{SL}} \mathrm{H})$

Unlike ( $\underline{\mathrm{L}} \mathrm{SL})$, ( $\underline{\mathrm{H}} \mathrm{SL})$ does not alternate with $(\underline{\mathrm{H}})$ due to the restriction against a resultant tri-consonantal sequence.

In sum, the alternation of high vowels in the non-final environment in shown to result from a series of prosodic markedness conditions, namely constraints on foot form. The alternating foot shapes are ranked for well-formedness following the Trochaic Markedness Hierarchy proposed here for Québécois, based on the relative ranking of the three quantitative criteria: minimum, evenness, and dominance.

(61) Trochaic Markedness Hierarchy (TMH)

(L), $(\underline{\mathrm{L}} \mathrm{L}),(\underline{\mathrm{H}}) \gg>(\underline{\mathrm{H}} \mathrm{L}),(\underline{\mathrm{L}} \mathrm{H}) \gg>(\underline{\mathrm{L}} \mathrm{SL}),(\underline{\mathrm{H}} \mathrm{SL}) \gg(\underline{\mathrm{SL}} \mathrm{L}),(\underline{\mathrm{SL}} \mathrm{H}) \gg(\underline{\mathrm{SL}} \mathrm{SL}) \gg>\{\underline{\mathrm{SL}}\}$

In sum, the first group of the most well-formed foot shapes instantiates the unmarked feet of French: (L) and (프) - the two feet co-extensive with a syllable, and ( $\underline{L} \mathrm{~L})$ - a derived foot, the most well-formed for forms in which branching occurs. The next pair of derived shapes, $(\underline{H} \mathrm{~L})$ and $(\underline{L} \mathrm{H})$, are less well-formed, but are more well-formed than the rest of the foot shapes, given that they do not contain any SL-rhymes. Although the former only violates evenness while the latter both evenness and dominance, there is no empirical evidence or an otherwise compelling formal consideration to separate them into two distinct markedness categories. The next two groups are distinguished by the presence of a single SL-rhyme. While there is an empirical basis for a distinction between 
(L SL) and (SL L), for consecutive hypomoraic rhymes, there is no empirical distinction between ( $\underline{\mathrm{L}} \mathrm{SL})$ and (ㅂ SL) on the one hand, and (SL L) and (SL H), on the other. The next highest markedness shape is (SL SL), containing two SLrhymes. In feet containing consecutive hypomoraic rhymes, this foot shape is the most marked. Finally, the degenerate foot $\{\mathrm{SL}\}$ is the most marked foot on the hierarchy. The subsections of the hierarchy as applied to representative forms are summarized below:

(62) Trochaic markedness and surface forms

(a) (L L) $\gg$ (L SL): [amitje] > [amitje]

(b) (L L), (H) $>$ (L SL): (ka.mi) (zol), (kam) (zol) $\gg$ (ka.mi) (zol)

(c) $(\underline{\mathrm{L}} \mathrm{L}) \gg(\underline{\mathrm{SL}} \mathrm{L})$ : [nymero] $\gg$ [nymero]

(d) $(\underline{\mathrm{H}} \mathrm{L}) \gg(\underline{\mathrm{H}} \mathrm{SL})$ : [balbysje] $\gg$ [balbysje]

(e) $(\underline{\mathrm{L}} \mathrm{H})>(\underline{\mathrm{SL}} \mathrm{H})$ : [syporte] $>$ [syporte]

(f) (L) $\gg\{$ SL $\}$ : [tupi] $\gg>$ tupi]

(g) $(\underline{\mathrm{L}} \mathrm{L})>(\underline{\mathrm{L}} \mathrm{SL})>(\underline{\mathrm{SL}} \mathrm{L}) \gg(\underline{\text { SL SL}})$ : [difisil] $>>[$ difisIl] $>>[$ di.fi.sil $\gg>[$ dI.fI.sIl]

\section{Conclusion and direction of further research}

This paper has presented a prosodic motivation of the tense/lax/ $\varnothing$ alternation within a unified context. In sum, this treatment of the variable Québécois high vowel distribution views alternating shapes of the minimally monomoraic trochee aligned with multiple attested realizations of these vowels. In other words, it is the prosodic structure that allows for and supports the attested generalizations and regulates their well-formedness. As such, under this view, the TMH ranking of $(\underline{\mathrm{L}} \mathrm{L})>(\underline{\mathrm{L}} \mathrm{SL})$ correctly predicts that non-final open syllables are more likely to surface with a tense vowels, barring harmonic processes, all the while allowing for the existence of lax high vowels in open syllables. Medial syllable deletion is also shown to be prosodically-induced under the TMH. Future work on the subject would gather robust and systematic empirical evidence to further validate the proposed TMH.

Acknowledgements: I want to thank my dissertation director, Jean-Pierre Montreuil, for his indefatigable support and guidance throughout all stages of the work leading to this manuscript, as well as the members of my doctoral dissertation committee: David Birdsong, Carl Blyth, Megan Crowhurst, and Knud Lambrecht. Many thanks go to the reviewers of the manuscript for their many insights and suggestions. 


\section{References}

Abu-Abbas, Khaled H., Thaer T. Al-Kadi \& Feda Y. Al-Tamimi. 2010. On three -rb- language games in Arabic. Argumentum 6. 76-90.

Anttila, Arto \& Young-mee Cho. 1998. Variation and change in Optimality Theory. Lingua 104. 31-56.

Archangeli, Diana \& Terence Langendoen, (eds.) 1997. Optimality theory. An overview. Oxford: Blackwell.

Archibald, John. 1996. The Acquisition of Syllable Weight and Foot Type. Paper presented at the Fifth Conference on Laboratory Phonology, Northwestern University, July 1996.

Bosworth, Yulia. 2011. Weight and Feet in Québécois. Ph.D. Dissertation. University of Texas at Austin.

Bullock, Barbara E. 1994. Does the French syllable have weight? In Michael Mazzola (ed.), Issues and theory in Romance Linguistics, 3-15. Washington, D.C: Georgetown University Press.

Bullock, Barbara E. 1998. The myth of equivalence. Where two lights do not make a long. In Josée Lema \& Esthela Trevino (eds.), Theoretical analyses on Romance languages, 53-70. Amsterdam/ Philadelphia: Benjamins.

Cedergren, Henrietta J. \& Louise Simoneau. 1985. La chute des voyelles hautes enfrançais de Montréal: 'As-tu entendu la belle syncope? In Monique Lemieux \& Henrietta J. Cedergren (eds.), Les tendances dynamiques du français parlé à Montréal, 57-144. Montréal: Office de la langue française

Charette, Monique. 1991. Conditions on phonological government. Cambridge: Cambridge University Press.

Cho, Young-Mee Yu \& Tracy Holloway King. 2003. Semi-syllables and universal syllabification. In Caroline Féry \& Ruben van de Vijver (eds.), The syllable in optimality theory, 183-213. Cambridge: Cambridge University Press

Clements, G.N. 1988. The role of the sonority cycle in core syllabification.Working Papers of the Cornell Phonetics Laboratory, 1-68.

Côté, Marie-Hélène. 2008. La syllabation et le relâchement des voyelles hautes en syllabe nonfinale en français québécois. Paper presented at Journées PFC, Tulane University.

Couturier, Jean-François. 1998. Contribution of phonetic criteria in the linguistic study of the lowering of québécois French high vowels. Ph.D. Dissertation, University of Montréal, Montréal.

Crosswhite, Katherine M. 2000b. The Analysis of Extreme Vowel Reduction. UCLAWorking Papers in Linguistics 4, 1-12.

Déchaine, Rose-Marie. 1991. Stress in Québécois: evidence from high vowels. Papers from the Regional Meetings, CLS, 27, 107-118.

Delattre, Pierre. 1966. Studies in French and comparative phonetics. The Hague: Mouton \& Co.

Dumas, Denis. 1974. Durée vocalique et diphtongaison en français québécois. Cahier de Linguistique 4. 13-52.

Dumas, Denis. 1976. Québec French High Vowel Harmony: The Progression of a Phonological Rule. CLS 12. 161-168.

Dumas, Denis. 1978. Phonologie des réductions vocaliques en français québécois.

Ph.D. dissertation, Université de Montréal. 
Dumas, Denis. 1981. Structure de la diphtongaison québécoise. Revue canadienne de linguistique 26. 1-61.

Dumas, Denis. 1987. Nos façons de parler. Sillery: Presses de l'Université du Québec.

Féry, Caroline. 2003. "Final Devoicing and the stratification of the lexicon in German". In Weijer, Jeroen van de, Vincent J. van Heuven \& Harry van der Hulst (eds.), The phonological spectrum: Volume I: segmental structure, 145-169. Amsterdam/ Philadelphia: John Benjamins Publishing Company.

Fónagy, Ivan. 1979. L’accent français: accent probabilitaire. In Ivan Fónagy \& Pierre Léon (eds.), L'accent en français contemporain, 123-233. Montréal: Didier.

Fujimura, Osamu. 1979. An analysis of English syllables as cores and affixes. Zeitschrift für Phonetik, Sprachwissenschaft und Kommunikationsforschung, 32: 471-476.

Fouché, Pierre. 1959. Traité de pronunciation française, 2nd ed. Paris: Klincksieck.

Gendron, Jean-Denis. 1966. Tendances phonétiques du français parlé au Canada. Paris and Québec: Lincksieck and PUL.

Goad, Heather \& Meagan Buckley. 2006. Prosodic structure in child French. Evidence for foot. Catalan Journal of Linguistics 5. 109-142.

Gordon, Matthew. 2002b. A phonetically-driven account of syllable weight. Language 78. 51-80.

Gordon, Matthew. 2004b. Syllable weight. In Bruce Hayes, Robert Kirchner \& Donca Steriade (eds.), Phonetic Bases for Phonological Markedness, 277-312. Cambridge: Cambridge University Press.

Hayes, Bruce. 1989b. Compensatory lengthening in moraic phonology. Linguistic Inquiry 20. 253-306.

Hayes, Bruce.1995. Metrical stress theory. Principles and case studies. Chicago: University of Chicago Press.

Hyman, Larry. 1985. A theory of phonological weight. Dordrecht: Foris.

Itô, Junko \& Armin Mester. 1992. Weak layering and word binarity. In Takery Homma, Masao Okazaki, Toshiyuki Tabaka \& Shin-ichi Tanaka (eds.), A new century of phonology and phonological theory, 26-65. Tokyo: Kaitakusha.

Kager, René. 1997. Rhythmic vowel deletion in Optimality Theory. In Iggy Roca (ed.), Derivations and constraints in phonology, 463-499. Oxford: Oxford University Press.

Kager, René. 1999. Optimality theory. Cambridge: Cambridge University Press.

McCarthy, John J. \& Alan Prince. 1993a. Generalized Alignment. In Geert Booij \& Jaap van Marle (eds.), Yearbook of morphology, 79-153. Dordrecht: Kluwer. Also ROA-7.

McCarthy, John \& Alan Prince. 1993b. Prosodic Morphology I: Constraint Interaction and Satisfaction. Rutgers Technical report TR-3. New Brunswick, Rutgers University Center for Cognitive Science.

McCarthy, John \& Alan Prince. 1995a. Faithfulness and reduplicative identity. In Beckman, WalshDickey, and Urbanczyk, 249-384.

Montreuil, Jean-Pierre. 1992. An underspecification analysis of two French vowel systems. In Theoretical analyses in Romance linguistics (Current Issues in Linguistic Theory 74), Terrel A. Morgan \& Christiane Laeufer (eds.), Amsterdam: Benjamins, 115-127.

Montreuil, Jean-Pierre. 1993. Prosody, morphology and foot formation in Modern French. Paper presented at the Linguistic Symposium on Romance Languages, Northern Illinois University.

Montreuil, Jean-Pierre. 1995a. Weight and length in Conservative Regional French. Lingua, 95, 77-96 
Montreuil, Jean-Pierre. 2004a. Fragmenting weight in Scottish English. In Monica Pulki (ed.), La Tribube Internationale des Langues Vivantes, 36, 114-122. Paris.

Montreuil, Jean-Pierre. 2004b. The Computation of weight in English and in Québec French. First PAC Workshop 23-24 April 2004, Université de Toulouse le Mirail.

Montreuil, Jean-Pierre. 2005. Le poids phonologique en français québécois. Ms., University of Texas, Austin.

Morén, Bruce. 2003. Weight typology: An optimality theoretic approach. The Linguistic Review 20. 281-304.

Paradis, Claude \& Denise Deshaies. 1991. Rules of stress assignment in Québec French: Evidence from perceptual data. Language Variation and Change 2. 135-154.

Phinney, Marianne. 1980. Evidence for a Rhythm Rule in Québec French. Proceedings of the Tenth Meeting of the North Eastern Linguistic Society, Cahiers linguistiques d'Ottawa 9. 369-382.

Plénat, Marc. 1987. On the structure of rhyme in Standard French. Linguistics 25. 867-887.

Poliquin, Gabriel. 2006. Canadian French Vowel Harmony. Ph.D. dissertation, Harvard University.

Prince, Alan \& Paul Smolensky. 1993/2002/2004. Optimality Theory: Constraint Interaction in Generative Grammar. Blackwell (2004); Technical Report, Rutgers University Center for Cognitive Science and Computer Science Department (2002), University of Colorado at Boulder (1993).

Selkirk, Elizabeth. 1978. The French foot: on the status of "mute" e. Studies in French Linguistics 1. 141-150.

Scullen, Mary Ellen. 1997. French prosodic morphology: A unified account. Bloomington, Indiana: Indiana University Linguistics Club Publications.

Walker, Douglas. 1984. The pronunciation of Canadian French. Ottawa: University of Ottawa Press.

Zec, D. 2003. Prosodic weight. In Féry, Caroline \& Ruben van de Vijver (eds.), The syllable in optimality theory, 123-143. New York: Cambridge University Press. 